\title{
22. BIOGENIC AND TERRIGENOUS SEDIMENTATION AT CEARA RISE, WESTERN TROPICAL ATLANTIC, SUPPORTS PLIOCENE-PLEISTOCENE DEEP-WATER LINKAGE BETWEEN HEMISPHERES ${ }^{1}$
}

\author{
Sara E. Harris, ${ }^{2}$ Alan C. Mix, ${ }^{2}$ and Terri King ${ }^{3}$
}

\begin{abstract}
Calcium carbonate percentages at five Ceara Rise sites were estimated at 1- to 2-k.y. intervals over the past 5 m.y., using reflectance spectroscopy and magnetic susceptibility proxies. From these estimates and detailed correlations between sites, gradients of calcite and terrigenous sediment accumulation rates in a depth transect of sites reveal variations in local climate and calcite dissolution related to deep-water masses. Relative to shallow sites on the southern Ceara Rise, accumulation rates of terrigenous sediments at deeper sites near the Amazon Fan were higher during glacial periods. Analogous variations in terrigenous sedimentation before the expansion of Northern Hemisphere ice sheets $\sim 3$ m.y. ago suggests that tropical climate cycles occurred independently of polar glaciation. Decreasing accumulation rates of calcite with increasing water depth reveal patterns of carbonate dissolution, which varied on orbital time-scales (10-100 k.y. periods) throughout the Pliocene-Pleistocene. Maximum dissolution at deep relative to shallow sites occurred in the transition from interglacial to glacial conditions, and maximum preservation occurred during global warming, at all orbital periods. If the local dissolution gradient is linked to relative contributions of North Atlantic Deep Water and Antarctic Bottom Water, this phasing of events confirms a key prediction of SPECMAP that deep-water adjustments may translate climate changes between hemispheres. Dissolution and preservation events, however, may also reflect a transient response to a net flux of organic matter between the continents and the oceans during ice-age climate transitions.
\end{abstract}

\section{INTRODUCTION}

Ocean thermohaline circulation patterns change on glacial-interglacial time scales (e.g., Curry and Lohmann, 1983; Oppo and Fairbanks, 1987; Curry et al., 1988; Raymo et al., 1990). Much of the evidence for these changes comes from stable carbon isotopes, a nutrient-like tracer in benthic foraminifers. Carbon isotopes can be affected by both local/regional circulation and by global shifts in the mean isotopic value of the ocean. This global mean signal also correlates with Pleistocene glacial cycles. Shackleton (1977) suggested that this global signal reflected ice-age deforestation in the world's major rain forests, which would add isotopically light carbon to the atmosphere and ocean. Because the effect described by Shackleton should occur on the same time scales globally, one can look at local circulation effects with carbon isotope gradients. Carbon isotope records from the Atlantic generally indicate a reduction in North Atlantic Deep Water (NADW) production during glacial maxima (Curry and Lohmann, 1983; Curry et al., 1988; Raymo et al., 1990).

SPECMAP (Imbrie et al., 1992; 1993) quantified relationships between several climate proxies and global ice volume (as reflected in oxygen isotope records). SPECMAP found earlier climate transitions in the southern than Northern Hemisphere, and predicted that deep-water circulation translates early climate transitions from the Nordic Seas to the southern ocean. A problem with this prediction is that reconstructions of deep-water circulation (for example, $\%$ NADW relative to southern source water in the North Atlantic based on carbon isotopes; Raymo et al., 1990) vary with the wrong phase. Can we reconcile these differences? Perhaps the deep-water

${ }^{1}$ Shackleton, N.J., Curry, W.B., Richter, C., and Bralower, T.J. (Eds.), 1997. Proc. ODP, Sci. Results, 154: College Station, TX (Ocean Drilling Program).

${ }^{2}$ College of Oceanic and Atmospheric Sciences, Oregon State University, Corvallis, OR 97331, U.S.A. sharris@oce.orst.edu

${ }^{3}$ Graduate School of Oceanography, University of Rhode Island, Narragansett, RI 02882, U.S.A. records were too close to the source of North Atlantic Deep Water to track the large-scale circulation of NADW. For example, Mix et al. (1995c) argued that deep-water export from the South Atlantic was decoupled from formation processes in the north. It is this large-scale circulation process that would translate signals between the Northern and Southern Hemispheres as envisioned by Imbrie et al. (1992; 1993). Perhaps the complex blend of records used in the carbon isotope indices, which requires differences between three different stable isotope records, preclude precise phase calculations because the global component of carbon isotope variation is not sufficiently known.

Ceara Rise provides an opportunity to test the SPECMAP hypothesis, because it is bathed at different depths by NADW and Antarctic Bottom Water (AABW), thus monitoring the import of these water masses far from either source. At present, AABW is much more corrosive to calcite, and a strong dissolution gradient marks the deep water-mass boundary (Curry and Lohmann, 1990). The dissolution signal, like carbon isotopes, probably contains some global component as well as local water mass component. An argument for dominance by local circulation effects is that carbonate dissolution records from the Atlantic are often out of phase with dissolution events in the $\mathrm{Pa}$ cific (Crowley, 1985). This would not be expected if the major dissolution signal were global (Peterson and Prell, 1985). Decreased production of NADW or a northward shift of AABW would cause the lysocline to shoal at Ceara Rise, which would cause increased dissolution at depth.

\section{Setting}

Ceara Rise is located in the western tropical Atlantic (Fig. 1). Drill sites, at water depths from $\sim 3.0$ to $4.4 \mathrm{~km}$ span the present-day mixing zone between NADW and AABW (Table 1). The transition between these water masses is presently between 4.0 and $4.5 \mathrm{~km}$ depth, with NADW overlying AABW.

Sediments on Ceara Rise come from two main sources: biogenic carbonate, produced in the upper water column by calcareous plank- 

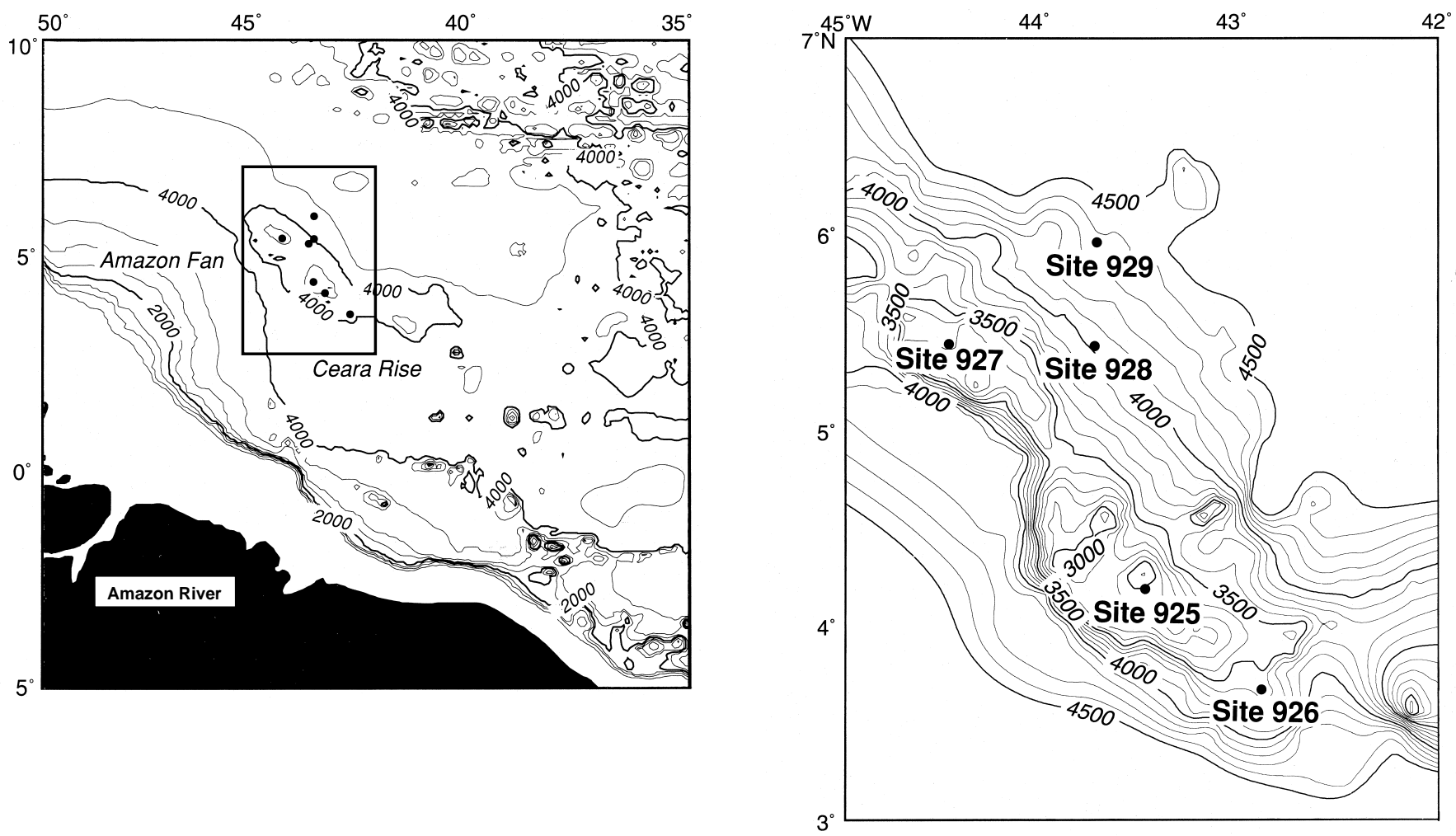

Figure 1. Maps showing locations and depths of Ceara Rise sites. Dominant sediment types deposited here are biogenic calcium carbonate from surface waters and terrigenous material from South America, primarily from the Amazon drainage. The assumption in drilling this depth transect is that carbonate input from surface water productivity is equal at all sites. See Table 1 for water depths.

Table 1. Site locations and depths.

\begin{tabular}{cccc}
\hline Site & Latitude & Longitude & $\begin{array}{c}\text { Water depth } \\
(\mathrm{m})\end{array}$ \\
\hline 925 & $4^{\circ} 12^{\prime} \mathrm{N}$ & $43^{\circ} 29^{\prime} \mathrm{W}$ & 3041 \\
926 & $3^{\circ} 43^{\prime} \mathrm{N}$ & $42^{\circ} 54^{\prime} \mathrm{W}$ & 3598 \\
927 & $5^{\circ} 28^{\prime} \mathrm{N}$ & $44^{\circ} 29^{\prime} \mathrm{W}$ & 3314 \\
928 & $5^{\circ} 27^{\prime} \mathrm{N}$ & $43^{\circ} 45^{\prime} \mathrm{W}$ & 4010 \\
929 & $5^{\circ} 59^{\prime} \mathrm{N}$ & $43^{\circ} 44^{\prime} \mathrm{W}$ & 4358 \\
\hline
\end{tabular}

ton, and terrigenous clays and quartz coming mostly from the Amazon and other South American Rivers, although trace amounts may come from Africa by eolian transport (Balsam et al., 1995). We assume that the geographic area covered by the sites is small enough that the input of biogenic carbonate from overlying surface waters is approximately equal at all the sites. Differences in accumulation rates of calcite at sites of varying depths can therefore serve as a index of carbonate dissolution.

\section{METHODS \\ Proxy Data}

We used nonintrusive proxies (i.e., rapid measurements that do not consume sediment) to construct detailed estimates of sediment variability over long time scales. The proxies, reflectance spectroscopy and magnetic susceptibility, were measured at 5-10-cm intervals (a temporal sampling interval of a few thousand years). This resolution required more than 3000 measurements per site covering the past five million years, more than 15,000 analyses. Such a large number of samples would be inefficient to measure discretely in the laboratory using traditional chemical methods. A trade-off for high temporal resolution and long time series is precision. While errors on laboratory calcium carbonate measurements by coulometer are typically better than 1\% (e.g., Ostermann et al., 1990), errors on our proxy estimates average $5.5 \%$. However, given the range of carbonate content in Ceara Rise sediments $(0 \%-90 \%)$, this precision is acceptable.

Reflectance spectra were measured on split cores using a secondgeneration automated instrument developed at Oregon State University (an improved version of Mix et al., 1992). This type of instrument was first used in applications to marine sediment cores on Ocean Drilling Program (ODP) Leg 138 in the eastern equatorial Pacific (Mix et al., 1995a). The newer instrument has an expanded wavelength range, higher spectral resolution, and a new detector that provides approximately a ten-fold increase in signal-to-noise ratios over the prototype instrument used on Leg 138. It measures 1024 channels of reflected light from the unprepared surfaces of split cores. Wavelengths measured range from 250 to $950 \mathrm{~nm}$ (ultravioletvisible-near infrared) with a spectral resolution of $0.68 \mathrm{~nm}$.

During measurement, a split sediment core moves along a track and is measured at specified depth intervals. An integrating sphere with ports for a light source (quartz-tungsten-halogen and deuterium bulbs) and detector (charge-coupled device) is automatically lowered to the core surface at each sampling interval. The surface is sensed by an array of electrical conductivity probes and strain gauges. This combination of "landing" sensors provides a means to position the integrating sphere a consistent distance from the core surface. Soft sediment surfaces with low wet bulk density are easily sensed by conductivity probes. More compacted sediment surfaces from deeper sections are often sensed by triggering a strain threshold. 
Each reflectance spectrum measurement is a combination of diffuse and specular reflectance from a circle approximately $2 \mathrm{~cm}$ in diameter. A light trap for specular reflectance is possible with this instrument, although the surface roughness of unprepared cores makes it difficult to eliminate the specular component. A $2-\mathrm{cm}$ spot is a reasonable sample size to smooth effects of bioturbation (i.e., individual burrows) without seriously degrading the paleoclimatic signal in these sediments.

Percent reflectance is calculated with reference to a background measurement (lights off), an internal white standard (Spectralon $\left.{ }^{\circledR}\right)$ and four external standards with known reflectivities (roughly $2 \%$, $40 \%, 75 \%$, and $100 \%$ reflectance). The external standards are measured in exactly the same way as split core samples, providing a means to calculate percent reflectance through the $0 \%-100 \%$ reflectance range at each wavelength measured.

Reflectance measurements were made during August and September, 1994, at the ODP Core Repository in Bremen, Federal Republic of Germany, approximately 6 months postcruise. Some oxidation of iron sulfides occurred between April and August, although comparisons to shipboard reflectance measurements (visible range only, 400-700 nm) indicate that the spectra 0-5 Ma were not significantly altered by core storage. Magnetic susceptibility was measured shipboard on whole cores with the multisensor track on the JOIDES Resolution. We used a combination of reflectance and magnetic susceptibility to develop proxy carbonate signals.

\section{Calibrating the Proxies}

Multiple linear regression techniques define empirical relationships between calcium carbonate content and proxy variables. The "ground truth" data used for calibration are about 2200 chemical measurements of calcium carbonate percentages, from four sources (our measurements, Table 2, on CD-ROM, this volume; Curry and Cullen, Chapter 12, this volume; King et al., Chapter 23, this volume; shipboard measurements [available on the Leg 154 Initial Reports CD-ROM]). If reflectance or susceptibility measurements did not match discrete sample depths exactly, but were within $5 \mathrm{~cm}$, we interpolated the proxy data between adjacent samples.

Input terms to the regression fall into three categories: (1) percentage reflectance in block-averaged, 10-nm-wide bands, (2) first derivatives of the reflectance spectrum with respect to wavelength in block-averaged, 10-nm-wide bands, and (3) magnetic susceptibility (in SI units). We also input the square of each variable to allow the regression equations to simulate weak nonlinearity in the relationship to carbonate. Inclusion of squared terms improved statistical relationships in all cases. From all the above input terms, those terms included in the equations (Table 3) were selected stepwise, beginning with the term most highly correlated with measured $\% \mathrm{CaCO}_{3}$. Terms were retained in regression equations only if significant above a $95 \%$ confidence level.

Why use reflectance and susceptibility together? Percent reflectance is a measure of "brightness" at a specific wavelength. Calcium carbonate is highly reflective across our wavelength range (Gaffey, 1986). Other trace components, for example biogenic opal, are also highly reflective. Many noncarbonate constituents (such as clays, oxides) are less reflective than carbonate, but may have a variety of spectral shapes. Percent reflectance is positively correlated with carbonate content and is the dominant term in all but one estimating equation reported here (Table 3, Eq. 6). The first derivative of the reflectance spectrum with respect to wavelength measures spectral shape, or changes in slope, which are affected primarily by noncarbonate sedimentary constituents, for example, iron oxides and oxyhydroxides (Deaton and Balsam, 1991). Magnetic susceptibility is roughly inversely correlated with carbonate content, because pure calcium carbonate has low susceptibility. It has different biases than reflectance, for example, it may be affected by sedimentary oxidation-reduction conditions. We found that the combination of these variables yields a more accurate estimate of calcium carbonate than any variable type alone.

The strategy used on Leg 138 (Mix et al., 1995a) for developing transfer functions was to divide the groundtruth data set into two parts: a calibration data set, from which a regression equation was developed, and a verification data set, which was used to test the equation using data not included in the initial regression. After early tests with this approach, which showed that (1) our calibrations work on uncalibrated data sets, and (2) the appropriate variables and number of terms in an equation, we combined these two subsets of the groundtruth data to obtain more robust results.

\section{Time-Series Analysis Methods}

We compare a dissolution index and a terrigenous dilution index with global ice volume (a Pacific benthic oxygen isotope record) in the frequency domain. All spectra were calculated using fast Fourier transform techniques (Bloomfield, 1976). Evolving spectra are compilations of approximately 80 power spectra. Each individual spectrum was calculated from a 1-m.y.-long time series beginning with 0-1 Ma. Successive time series overlap by all but 50 k.y. Overlapping the time series means that adjacent individual frequency spectra are not independent, but this presentation shows the frequency evolution of these signals over the past $5 \mathrm{~m}$.y. The age scales on evolving spectra represent the mean age of the time series chosen for spectral analyses (i.e., $0.5 \mathrm{Ma}$ indicates the average power spectrum for $0-1 \mathrm{Ma}$ ).

\section{RESULTS}

Our strategy is to develop high resolution time series of carbonate dissolution and noncarbonate dilution indices via comparisons of the proxy carbonate records among Ceara Rise sites. Steps to this end include (1) estimating proxy carbonate over the past 5 m.y., (2) expressing the proxy time series for each site on a common depth and age scale, (3) developing mass accumulation rate ratios for carbonate and noncarbonate, and (4) comparing these relative mass accumulation rates to global ice volume changes in the frequency domain.

\section{Calibrating the Equations}

The groundtruth carbonate percentage data set was subdivided in three ways: by site, by depth-in-hole, and by latitude. In the shallowest cores (i.e., Cores $1 \mathrm{H}-4 \mathrm{H}$ from multiple holes at one site), where many groundtruth samples were measured, better statistical results were obtained by separating the data by site than by combining data from different sites. The logic behind separating the calibration data set by depth-in-hole is (1) the amplitude of the magnetic susceptibility signal decreases downcore (a compaction effect), and (2) the dominant component in the noncarbonate fraction of the sediment changes downcore. By grouping data in depth (or time) the effects of compaction and changing noncarbonate sedimentation on reflectance and susceptibility are partially defrayed. Three calibration equations include data from more than one site. Data from moderate depths (approximately Cores $7 \mathrm{H}-12 \mathrm{H}$ in multiple holes) were grouped (Eq. 8), data from deep cores (13H or deeper) were grouped (Eq. 9), and Equation 10 (Fig. 2) includes all data from all sites.

Root-mean-square errors (RMSE) for Equations 1-9 range from $\pm 4 \%$ to $\pm 7 \%$. Equations from more deeply buried intervals generally have the smallest errors (Table 3 ). Ranges of measured carbonate values are also smaller in these data sets because few measured values had less than $20 \% \mathrm{CaCO}_{3}$. The low RMSE estimates for Equations 6, 7,8 , and 9 are due partially to limited ranges of carbonate values. The fraction of variance explained $\left(\mathrm{r}^{2}\right)$ in each calibration ranges from 
Table 3. Regression equations for estimating calcium carbonate percentages.

\begin{tabular}{|c|c|c|c|c|c|c|c|}
\hline $\begin{array}{c}\text { Equation } \\
\text { no. }\end{array}$ & $\begin{array}{c}\text { Site } \\
(\text { depth*) }\end{array}$ & $\mathrm{N}$ & Terms** & Coefficient & Intercept & $r^{2}$ & $\begin{array}{c}\text { RMSE } \\
(\%)\end{array}$ \\
\hline 1 & 925 (shallow) & 416 & $\begin{array}{l}\text { R440 } \\
\text { MS } \\
\text { MSsq }\end{array}$ & $\begin{array}{c}3.01 \\
-1.96 \\
0.035\end{array}$ & 17.92 & 0.74 & 6.6 \\
\hline 2 & 926 (shallow) & 347 & $\begin{array}{l}\text { R540 } \\
\text { MS } \\
\text { MSsq } \\
\text { R540sq } \\
\text { D760sq }\end{array}$ & $\begin{array}{c}6.00 \\
-2.55 \\
0.0435 \\
-0.0870 \\
9117.86\end{array}$ & -17.02 & 0.75 & 6.2 \\
\hline 3 & 927 (shallow) & 431 & $\begin{array}{l}\text { R890 } \\
\text { D550 } \\
\text { D510 } \\
\text { D520sq }\end{array}$ & $\begin{array}{r}2.62 \\
-210.33 \\
265.57 \\
-1293.04\end{array}$ & -21.86 & 0.71 & 5.8 \\
\hline 4 & 928 (shallow) & 434 & $\begin{array}{l}\text { R920 } \\
\text { D560 } \\
\text { D500 } \\
\text { D480sq } \\
\text { D610 } \\
\text { D650 } \\
\text { R920sq }\end{array}$ & $\begin{array}{r}4.26 \\
-324.24 \\
456.21 \\
10332.27 \\
701.39 \\
-621.00 \\
-0.03\end{array}$ & -41.75 & 0.69 & 6.8 \\
\hline 5 & 929 (shallow) & 157 & $\begin{array}{l}\text { R900 } \\
\text { MS } \\
\text { MSsq } \\
\text { D620 } \\
\text { R550 } \\
\text { D600 } \\
\text { D600sq } \\
\text { D400sq }\end{array}$ & $\begin{array}{r}-7.89 \\
-1.51 \\
0.017 \\
1244.35 \\
10.87 \\
1167.43 \\
-14065.62 \\
194.57\end{array}$ & 6.47 & 0.81 & 5.5 \\
\hline 6 & 925 (moderate) & 131 & $\begin{array}{l}\text { MS } \\
\text { R480 } \\
\text { D640sq } \\
\text { D450 } \\
\text { R490 }\end{array}$ & $\begin{array}{r}-0.712 \\
7.58 \\
61108.15 \\
177.76 \\
-6.76\end{array}$ & 46.40 & 0.80 & 4.2 \\
\hline 7 & 926 (moderate) & 155 & $\begin{array}{l}\text { R470 } \\
\text { R450sq } \\
\text { D830 } \\
\text { D600sq } \\
\text { D540 } \\
\text { D770 } \\
\text { D540sq } \\
\text { D600 }\end{array}$ & $\begin{array}{c}6.91 \\
-0.113 \\
136.48 \\
56831.16 \\
-1550.58 \\
319.11 \\
7280.53 \\
-1018.20\end{array}$ & 40.43 & 0.76 & 4.7 \\
\hline 8 & All (moderate) & 337 & $\begin{array}{l}\text { R860 } \\
\text { R750sq } \\
\text { R880sq } \\
\text { D840sq } \\
\text { D450 } \\
\text { D600sq }\end{array}$ & $\begin{array}{r}7.14 \\
-0.26 \\
0.17 \\
-7881.54 \\
107.11 \\
9800.72\end{array}$ & -71.18 & 0.76 & 5.6 \\
\hline 9 & All (deep) & 156 & $\begin{array}{l}\text { R650 } \\
\text { R650sq } \\
\text { MS } \\
\text { R920 } \\
\text { R690 } \\
\text { R440 }\end{array}$ & $\begin{array}{r}13.59 \\
-0.05 \\
-0.82 \\
5.68 \\
-13.94 \\
-0.88\end{array}$ & -29.97 & 0.91 & 4.1 \\
\hline 10 & All samples & 2287 & $\begin{array}{l}\text { R640 } \\
\text { D530sq } \\
\text { R640sq } \\
\text { D530 } \\
\text { MS } \\
\text { MSsq }\end{array}$ & $\begin{array}{r}5.62 \\
1428.03 \\
-0.05 \\
-437.37 \\
-0.62 \\
0.002\end{array}$ & -31.19 & 0.83 & 7.6 \\
\hline
\end{tabular}

Notes: * Depth refers to depth below seafloor. $* *$ Term codes: $\mathrm{R}=\%$ reflectance term; $\mathrm{D}=$ first derivative of reflectance term; MS $=$ magnetic susceptibility; sq $=$ squared term; numbers are wavelengths in nm (e.g., R260sq = the square of \% reflectance in an averaged 10-nm-wide band centered at $260 \mathrm{~nm}$ ).

0.69 to 0.91 (Table 3). A significant fraction of the estimated error in the calibration is due to slight depth mismatches among the proxy and groundtruth data sets. Thus the RMSE values reported here are probably worst-case estimates.

These RMSEs compare favorably with previous efforts. Using similar techniques, the RMSE was $9.3 \%$ for estimating carbonate in the eastern Equatorial Pacific, where the carbonate signal is complicated by both opal and terrigenous sedimentary components (ODP Leg 138; Mix et al., 1995a). Lower errors here are partially due to the new instrumentation (see methods section) and probably also due to the simpler sedimentary regime at Ceara Rise. W.L. Balsam and B.C. Deaton (pers. comm., 1994) were able to estimate carbonate to within $6 \%$ at ODP Site 847 in the equatorial Pacific, using laboratory reflectance measurements on dried powdered samples, similar to our results.

Low carbonate values are most difficult to estimate, and have the largest residuals (Fig. 2). In these samples, carbonate contents are of- ten overestimated. This may be because both susceptibility and reflectance depend on the type of noncarbonate constituents present, which becomes important when the noncarbonate components dominate the total.

One might expect the best estimating equation to include all available laboratory data, thus increasing the degrees of freedom. Such a strategy seems reasonable in a limited geographical area such as Ceara Rise where the patterns of sedimentation are relatively simple (i.e., a balance between biogenic carbonate and terrigenous material). The equation including all the data (Eq. 10; Fig. 2; Table 3) has an $\mathrm{r}^{2}$ of 0.83 , the second highest of the ten equations, and an RMSE of $\pm 7.6 \%$, which is about $2 \%$ greater than our average error obtained using more localized data sets. Our experiments indicate that better results (in terms of error) can be obtained by limiting our calibration data sets in space and time as described above. This suggests that significant differences in the mineralogy of sediment sources exist even within this relatively small area. 
Equation 1

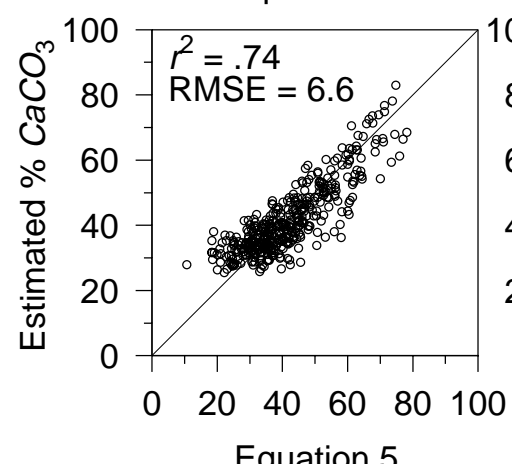

Equation 2

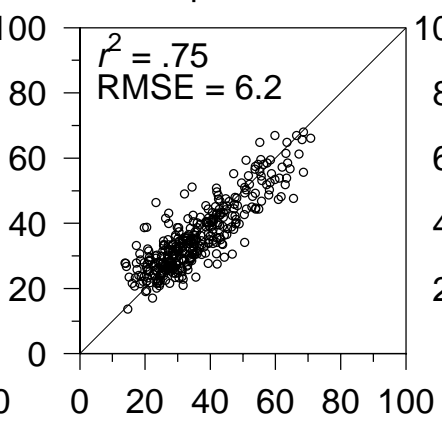

Equation 6
Equation 3

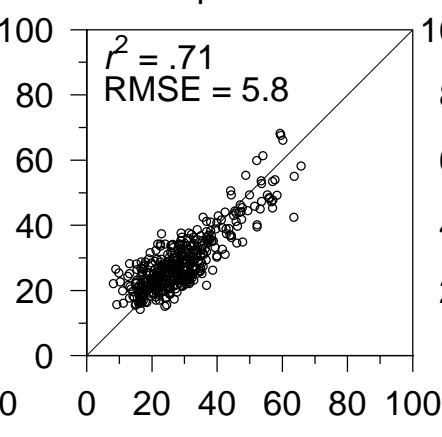

Equation 7
Equation 4
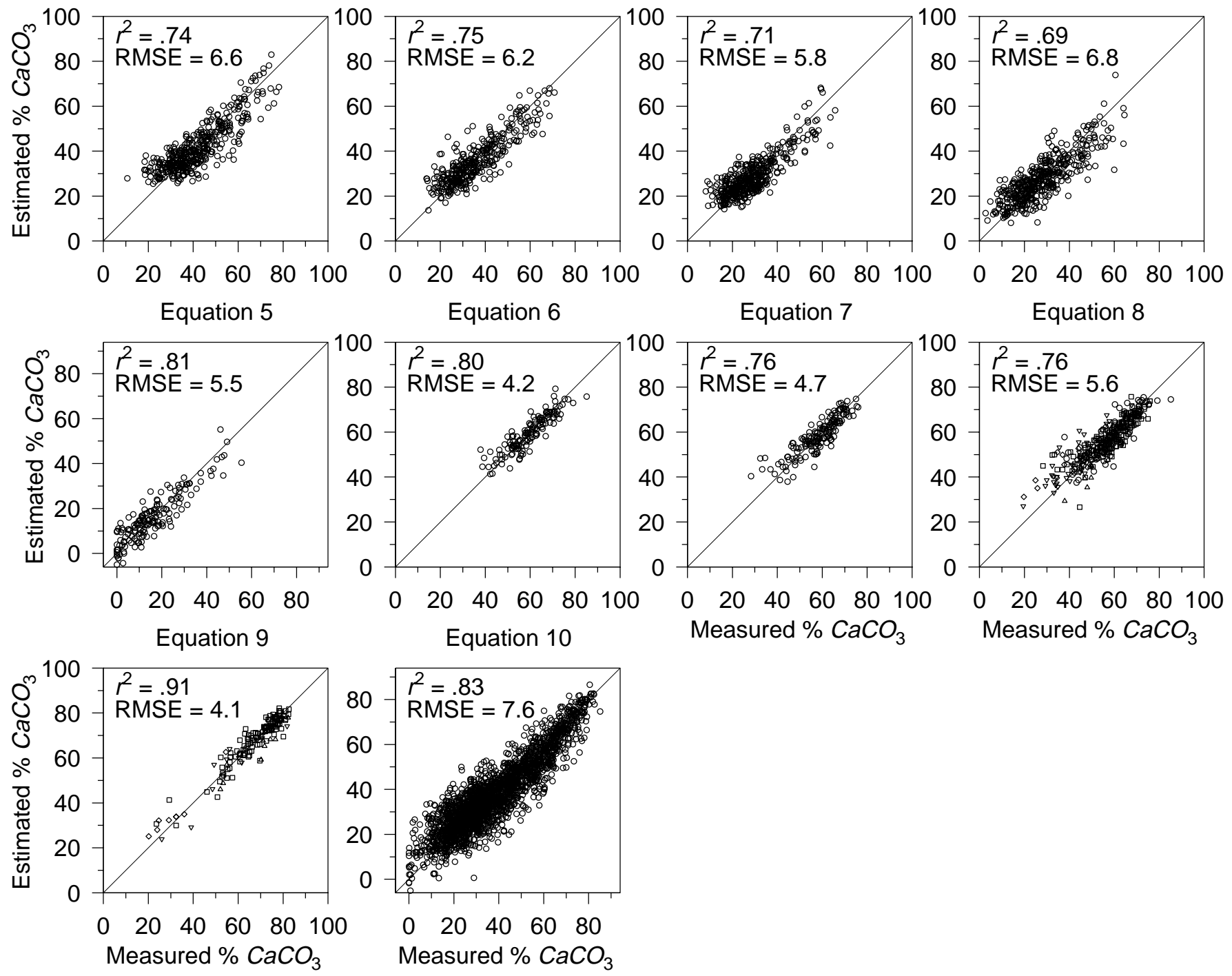

Figure 2. Measured calcium carbonate vs. estimated calcium carbonate for ten estimating equations. The solid line is a one-to-one line. Root-mean-square errors range from $4 \%$ to $7 \% \mathrm{CaCO}_{3}$. $\mathrm{R}^{2}$ values range from 0.69 to 0.91 . Best results were obtained by dividing the calibration data set into nine subsets by site, depth, and latitude. Equations 8, 9, and 10 combine data from different sites. Symbols for Equations 8 and 9 are as follows: circles = Site 925; squares = Site 926; triangles pointing up = Site 927; triangles pointing down $=$ Site 928; diamonds = Site 929. Equation 10 is a regional calibration including all data from all sites. See Tables 2, 3, and 4 for details and statistics of equations.

Sources of variability on Ceara Rise alone may be related to proximity to the Amazon Fan (the northern sites receive more terrigenous material than the southern sites) or compositional differences in the terrigenous fraction over time. These differences within a relatively small area imply that a global carbonate proxy based on reflectance and susceptibility is unlikely to be as accurate as local calibrations. The calibrations obtained here thus will probably not apply to different and more complex sedimentary regimes, such as those including significant fractions of opal or organic matter. W.L. Balsam and B.C. Deaton (pers. comm., 1994) noted the difficulty of obtaining an accurate regional carbonate calibration when they combined coretop and last glacial maximum (LGM) samples from sites throughout the Atlantic basin. They were able to estimate $\% \mathrm{CaCO}_{3}$ with an RMSE $=$ $11 \%$ using prepared discrete samples. Given the better success of their technique at a single site, Site 847 , they note that the Atlantic calibration suffers from interaction with varying noncarbonate constituents.
A simple comparison of the ten equations is to apply each to the other nine data sets and compare the fraction of variance explained, $r^{2}$ (Table 4). As expected, the highest $r^{2}$ values between measured and estimated percent carbonate for a given data set are obtained using the equation based on those data (the diagonal of Table 4). Two equations (Eqs. 6, 7) give poor estimations of other data sets, down to $\mathrm{r}^{2}$ equal to zero for Equation 7 applied to data set 9. The most robust equation is Equation 10, based on an average $\mathrm{r}^{2}$ across the 10 data sets (Table 4, column 11). This equation can be considered a regional calibration equation that could be applied to any Ceara Rise sediments. The trade-off for stability is a higher error associated with Equation 10.

What do our regression equations have in common? Most of the ten equations choose as their dominant term reflectance in either the lower visible wavelengths $(440-540 \mathrm{~nm})$ or the near infrared (860$920 \mathrm{~nm}$ ). Magnetic susceptibility is the first or second term in four equations. Equations at adjacent sites, for example, Sites 925 and 926 
Table 4. Compilation of $\mathbf{r}^{2}$ values for each equation applied to each calibration data set.

\begin{tabular}{|c|c|c|c|c|c|c|c|c|c|c|c|}
\hline \multirow{2}{*}{$\begin{array}{l}\text { Burial: } \\
\text { Sites: }\end{array}$} & \multicolumn{5}{|c|}{ Shallow } & \multicolumn{3}{|c|}{ Moderate } & \multirow{2}{*}{$\begin{array}{c}\text { Deep } \\
\text { all }\end{array}$} & \multirow{2}{*}{$\begin{array}{c}\text { All } \\
\text { all }\end{array}$} & \multirow[b]{3}{*}{ Mean } \\
\hline & 925 & 926 & 927 & 928 & 929 & 925 & 926 & all & & & \\
\hline Data set no.: & 1 & 2 & 3 & 4 & 5 & 6 & 7 & 8 & 9 & 10 & \\
\hline \multicolumn{12}{|l|}{ Equation no.: } \\
\hline 1 & 0.74 & 0.71 & 0.65 & 0.55 & 0.32 & 0.71 & 0.01 & 0.02 & 0.70 & 0.09 & 0.45 \\
\hline 2 & 0.72 & 0.75 & 0.67 & 0.60 & 0.40 & 0.73 & 0.01 & 0.01 & 0.77 & 0.06 & 0.47 \\
\hline 3 & 0.68 & 0.68 & 0.71 & 0.64 & 0.60 & 0.68 & 0.65 & 0.66 & 0.71 & 0.74 & 0.68 \\
\hline 4 & 0.69 & 0.67 & 0.70 & 0.69 & 0.65 & 0.55 & 0.54 & 0.61 & 0.48 & 0.69 & 0.63 \\
\hline 5 & 0.65 & 0.64 & 0.65 & 0.61 & 0.81 & 0.70 & 0.02 & 0.06 & 0.63 & 0.29 & 0.51 \\
\hline 6 & 0.09 & 0.07 & 0.21 & 0.12 & 0.33 & 0.80 & 0.08 & 0.22 & 0.41 & 0.18 & 0.25 \\
\hline 7 & 0.12 & 0.07 & 0.23 & 0.13 & 0.19 & 0.72 & 0.76 & 0.66 & 0.00 & 0.19 & 0.31 \\
\hline 8 & 0.41 & 0.34 & 0.58 & 0.47 & 0.48 & 0.75 & 0.71 & 0.76 & 0.18 & 0.55 & 0.52 \\
\hline 9 & 0.64 & 0.65 & 0.61 & 0.59 & 0.60 & 0.73 & 0.13 & 0.34 & 0.91 & 0.72 & 0.59 \\
\hline 10 & 0.71 & 0.70 & 0.68 & 0.60 & 0.60 & 0.72 & 0.73 & 0.72 & 0.88 & 0.83 & 0.72 \\
\hline
\end{tabular}

Notes: Equations and data sets are grouped by depth. Data set numbers correspond to equation numbers (the data set used to calibrate an equation). On the diagonal of the matrix are $r^{2}$ values for each equation applied to the corresponding calibration data set. The highest columnwise $r^{2}$ values are on the diagonal. The most robust equation based on mean $r^{2}$ is equation 10, which includes all data from all sites.

(Eqs. 1, 2) tend to be similar. Differences in the equations indicate that a variety of different minerals dilute carbonate and that the reflectance bands are not unique.

The common features in the equations highlight general relationships between carbonate content and the proxies. The variable most highly correlated to carbonate in these equations is usually some term for percentage reflectance (of differing wavelength) with a small positive coefficient. A positive relationship to reflectance is logical given the high reflectivity of calcium carbonate. All coefficients for susceptibility are negative in keeping with the general inverse relationship between magnetic susceptibility and carbonate content. Susceptibility squared has small positive coefficients in four equations. This squared term may be helpful in constraining the low end of estimated carbonate values.

Equations 3 and 4 have the highest mean $\mathrm{r}^{2}$ of the first nine equations ( 0.68 and 0.63 , respectively), and do not share the features of the other three "shallow" equations beyond the first percent reflectance term (Table 3 ). The second term in these equations, the first derivative at $550 \mathrm{~nm}$ and $560 \mathrm{~nm}$ with a negative coefficient, may be a clue to their success when applied to the other data sets. The first derivative near $550 \mathrm{~nm}$ is likely to be affected by the presence of iron oxides and oxyhydroxides (Deaton and Balsam, 1991). These constituents are present in higher amounts in low carbonate intervals, and color the sediment brownish red. Most of the sediments included in this study (0-5 Ma) are oxidized. Equations 3 and 4 therefore may record the presence of oxides in the noncarbonate fraction. This feature is common to all the sites over the time period studied, but may have a nonlinear relationship to carbonate, which could yield different sensitivities in different equations.

Data used to develop Equations 1-5 cover the same sediment burial depth range at each of the five sites (Cores $1 \mathrm{H}-4 \mathrm{H})$. Correlation trends (upper left corner of Table 4; $5 \times 5$ matrix) have some dependence on site depth and location. For example, $r^{2}=0.71$ for Equation 1 (Site 925) applied to data set 2 (Site 926). These two sites are located at the southern end of Ceara Rise and are geographically closest to one another. Correlations for the equation used in Site 925 (Eq. 1) applied to the remaining sites follow a water depth trend with the next highest correlation to data set $3\left(\right.$ Site $\left.927, \mathrm{r}^{2}=0.65\right)$ and the lowest correlation with data set 5 (Site 929, $\mathrm{r}^{2}=0.32$ ). Equation 2 (Site 926) follows a pattern similar to that of Equation 1. Equation 3 (Site 927) exhibits its highest correlations with the data sets from other shallow sites (Sites 925 and 926, data sets 1 and 2). However, it does a better job with the deepest site data (Site 929, data set 5) than with data from Site 928 (data set 4), which is closer in depth and geography. Its higher correlation with the data set from Site 929 may mean that these two sites receive a similar terrigenous component from the Amazon Fan.

\section{Downcore Estimates}

We estimated percent calcium carbonate content downcore at each site using Equations 1-9 (Fig. 3). The equations used for each range in depth and time at each site are tabulated in Table 5. Because these equations were calibrated in limited space and depth, transitions between equations at depth were necessary for each site. For intervals with gaps in laboratory carbonate data, (such as between "shallow" and "moderate" depth equations) we applied the two equations calibrated to either side of the gap and switched between regression equations where carbonate estimates given by these two equations were equal. Otherwise, the equation applied to a particular section of core was calibrated on data from that core.

Time series of estimated carbonate are visually similar among the sites. Using the orbitally tuned age models of Bickert and Tiedemann (this volume), most carbonate events occur synchronously at all locations. Assuming that the shallowest site (Site 925 at $3041 \mathrm{~m}$ ), which is presently well above the regional lysocline, has undergone minimal dissolution for this period, the similarity of $\% \mathrm{CaCO}_{3}$ variations at all depths implies that the first order carbonate cyclicity is primarily a productivity and/or dilution signal rather than a dissolution signal.

Although the shapes of the signals at all sites are similar, the range of carbonate values changes considerably with depth. Carbonate at the shallowest site (Site 925) ranges from about $20 \%$ to $80 \%$, while at the deepest site (Site 929) the range is about $0 \%-65 \%$. This difference could reflect either enhanced dilution at depth due to preferential input of noncarbonate material to the deeper sites, and/or to enhanced dissolution of carbonate at depth. To isolate these processes, we analyze the relative mass accumulation rates of carbonate and noncarbonate components at the deep and shallow sites, assuming equal export production of carbonate shells to all sites.

\section{Depth-Depth Correlations}

Our operational goal is to compare carbonate and noncarbonate accumulation rates across the depth transect on orbital time scales. This could be done in two ways. First, one could create a detailed age model in each site, calculate mass accumulation rates of each sedimentary component, and then compare absolute rates between sites. This method is not feasible, because age models are not sufficiently accurate in all sites to calculate absolute accumulation rates with suf- 


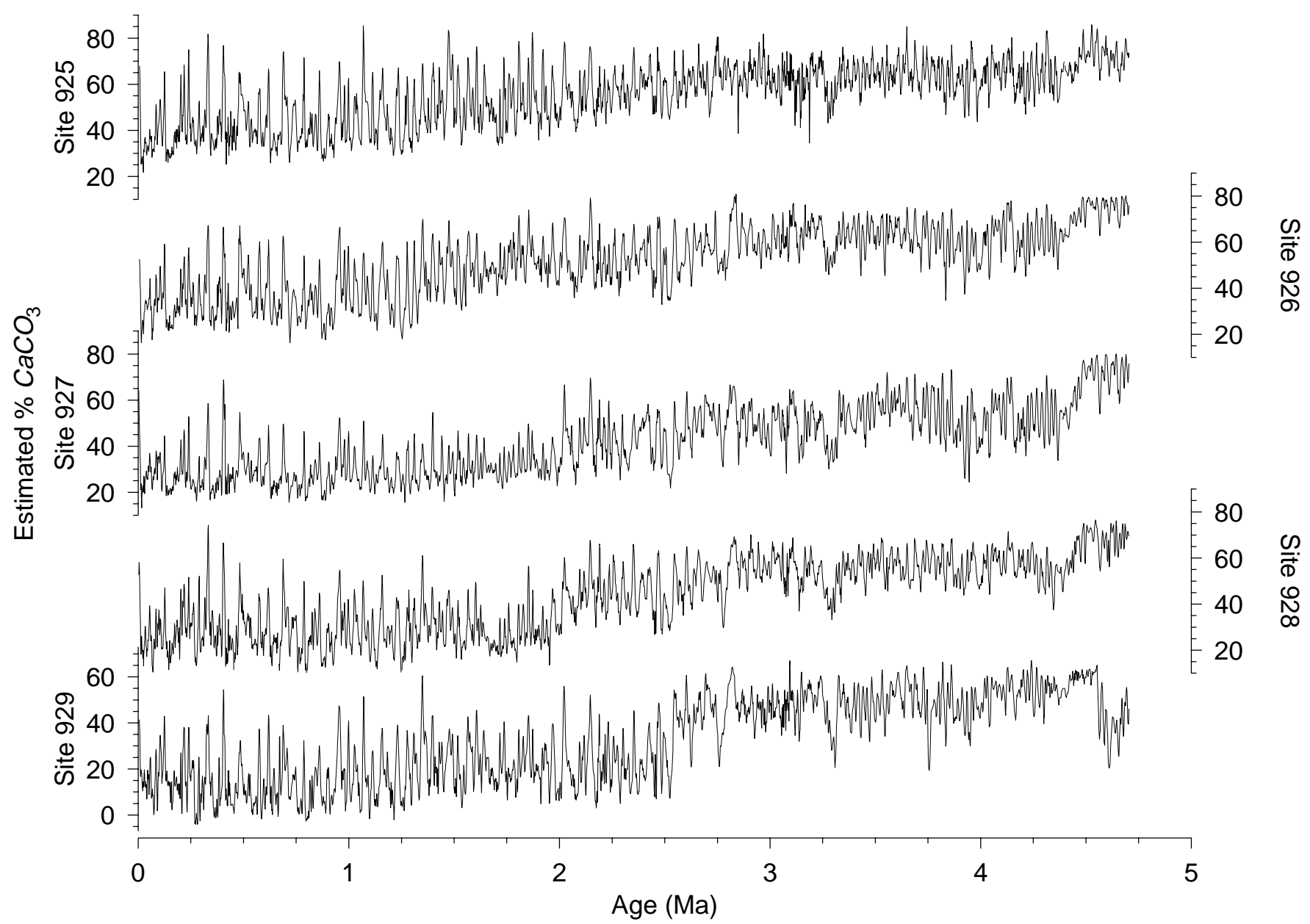

Figure 3. Downcore estimates of carbonate, 0-5 Ma, Sites 925-929 represented on orbitally tuned age models for each site (see Bickert and Tiedemann, this volume). Major carbonate events appear to occur synchronously across the depth transect, although the average carbonate content at shallow sites (Sites $925-$ 927), is higher than the average percent carbonate at the deeper sites. These differences are due to a combination of dissolution of carbonate at depth and dilution by terrigenous material primarily at the northern sites.

Table 5. Age and depth ranges for equations.

\begin{tabular}{cccr}
\hline Site & $\begin{array}{c}\text { Equation } \\
\text { no. }\end{array}$ & $\begin{array}{c}\text { Depth range } \\
(\mathrm{mcd})\end{array}$ & $\begin{array}{c}\text { Age range } \\
(\mathrm{Ma})\end{array}$ \\
\hline 925 & 1 & $0-65.03$ & $0-2.025$ \\
925 & 6 & $65.03-147.91$ & $2.025-4.710$ \\
926 & 2 & $0-48.98$ & $0-1.585$ \\
926 & 7 & $48.98-115.88$ & $1.585-3.731$ \\
926 & 9 & $115.88-154.07$ & $3.731-5.009$ \\
927 & 3 & $0-78.23$ & $0-2.023$ \\
927 & 8 & $78.23-137.40$ & $2.023-3.784$ \\
927 & 9 & $137.40-173.75$ & $3.784-5.008$ \\
928 & 4 & $0-65.26$ & $0-2.027$ \\
928 & 8 & $65.26-133.73$ & $2.027-4.269$ \\
928 & 9 & $133.73-150.11$ & $4.269-5.005$ \\
929 & 5 & $0-83.82$ & $0-2.545$ \\
929 & 8 & $83.82-133.25$ & $2.545-4.541$ \\
929 & 9 & $133.25-138.86$ & $4.541-4.908$ \\
& & &
\end{tabular}

ficient precision. Second, one could correlate records between sites in the depth domain, calculate the relative depth intervals occupied by a correlated event (i.e., the fractional accumulation rate relative to some reference site), and then apply an age model to this record. The assumption here is that events expressed as variations in sedimentary composition are correlated in time. We use this second method be- cause it allows much higher time resolution of events and provides robust estimates of relative accumulation rate independent of age model. If age models are improved in the future, the relative accumulation rate estimates made here can simply be recast onto the new time scale without changing their structure or amplitude.

A simple example to illustrate our strategy is shown in Figure 4. Figure 4A illustrates a simple time series, Signal 2, with labeled "events" (maxima and minima) that correspond to the events in a reference signal, Signal 1, in Figure 4B. Note that events "a" and "b" in Signal 2 occur shallower in depth than the same events in Signal 1. Event "c" occurs at a similar depth in both series, and events "d"-"f" occur shallower in Signal 1. Assuming that the events are synchronous, we can "map" one signal to the other in depth. The depth-depth map for these two signals is shown in Figure 4C (solid line). The straight dashed line represents the original linear depth-depth relationship. The map crosses the dashed line at event "c" which is synchronous in depth. The slope (or first derivative) of the curved line in Figure $4 \mathrm{C}$ is the relative sedimentation rate, or the sedimentation rate for Signal 2/sedimentation rate for Signal 1 (Fig. 4D). The slope of the depth-to-depth mapping function equals one where the sedimentation rates for the two signals are equal (at about 50 and 200 in arbitrary depth units). Where the slope is greater than one (the center part 
Figure 4. Example of depth-depth correlation strategy: (A) a "distorted" signal, (B) a "reference" signal, (C) a depth-depth mapping function of the "distorted" to "reference" signal, (D) the slope of the depth-depth map, or the relative sedimentation rate. See text for details.
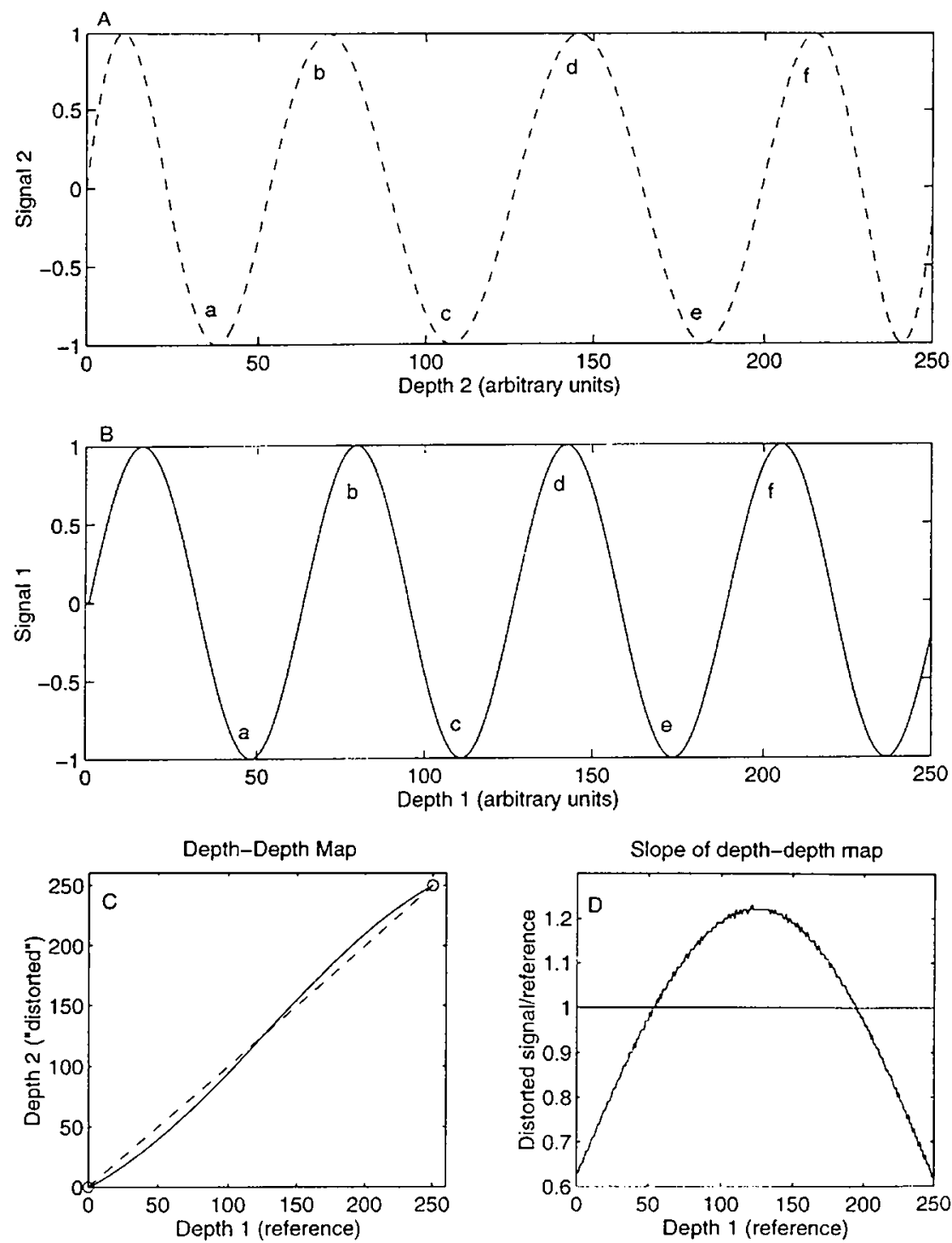

of Fig. 4D), the sedimentation rate is higher for Signal 2. Where the slope is less than one, the sedimentation rate is higher for Signal 1 (the ends of Fig. 4D). If, for example, Signal 1 is a reference "shallow" site and Signal 2 is a "deep" site, then the center part of Figure $4 \mathrm{D}$ could represent dilution of the carbonate signal at the "deep" site relative to the reference site (extra sediment). The ends of Figure 4D could represent dissolution at the "deep" site relative to the shallow site (removal of material).

To put all the sites onto a common depth scale, we correlated the percent carbonate records from each site to the record at Site 926, using the mcd (meters composite depth) scale from all cores (Fig. 5). Correlations of records are continuous, using inverse correlation method of Martinson et al. (1982). Site 926 is a reasonable choice for a depth reference site because it is intermediate in water depth among the sites and has the longest record of the reflectance proxy.

\section{Relative Sedimentation Rates}

Once all the sites are expressed relative to a common depth scale (that of Site 926) we can compare sedimentation rates at all the sites relative to any chosen reference. We choose Site 925 as the reference for relative sedimentation rate (Fig. 6) because as the shallowest site it has experienced the least carbonate dissolution of any of the sites.
Relative sedimentation rates are defined as $d\left(\right.$ depth $\left._{92^{*}}\right) / \mathrm{d}\left(\mathrm{depth}_{925}\right)$, where $92 *$ means $926,927,928$, or 929 . Thus values greater than one mean higher sedimentation rates, and values less than one mean lower sedimentation rates than those from equivalent ages in Site 925. These relative sedimentation rates are subsequently represented on the Site 926 age model (Bickert and Tiedemann, this volume).

The relative sedimentation rates for two of the northern sites (Sites 927 and 929 relative to 925 ) are greater than one during the Pleistocene (Fig. 6). High relative rates at these sites usually occur during glacial stages (as defined by oxygen isotopes). Both sites are deeper than Site 925 and therefore should be equally or more dissolved than the reference. Site 929 is the deepest site and is most likely to undergo dissolution. Regardless of a possible dissolution signal at depths greater than the reference site, the higher sedimentation rates at Sites 927 and 929 must be due to a greater influx of terrigenous material. This inference makes sense given the proximity of these Sites to the Amazon Fan. During glacial periods, lowered sea level would decrease the distance from the shelf edge to Ceara Rise, making increased transport of terrigenous material to the northern sites likely.

Sedimentation rates at Site 928 are similar to those at Site 925 during the Pleistocene (relative rates near 1.0). Site 928, although north of Site 925 , is located upslope of Site 929 and is "shadowed" from 

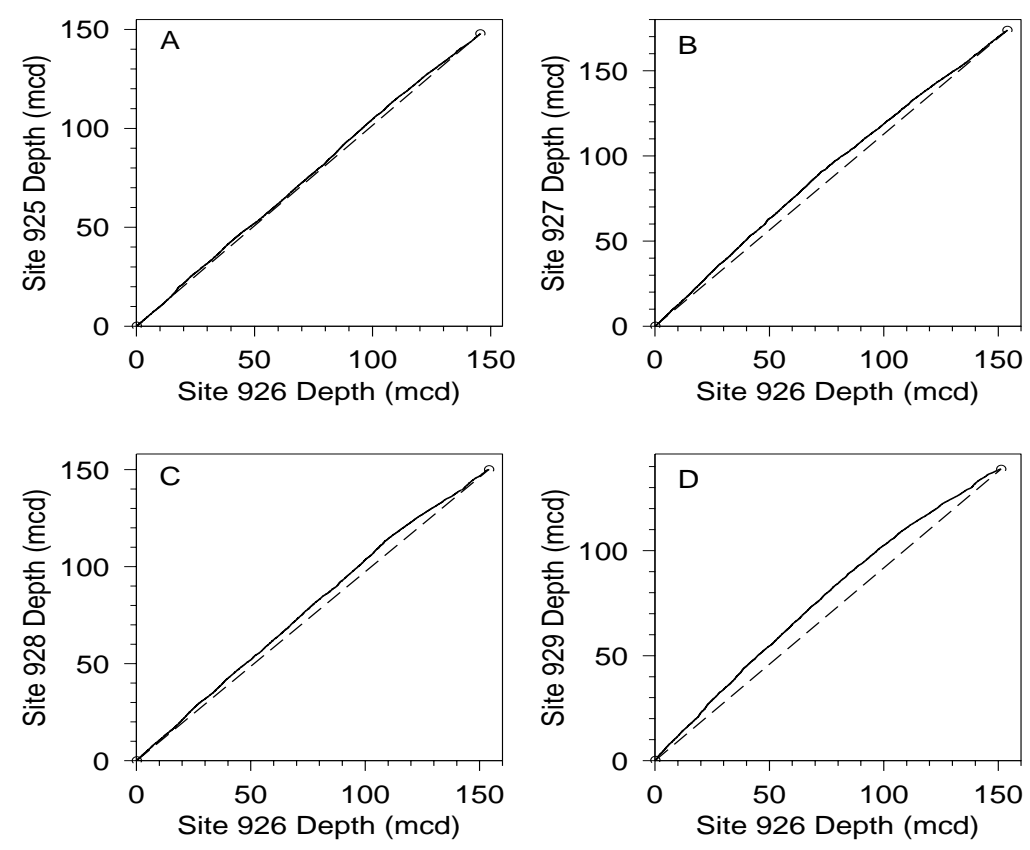

Figure 5. Depth-depth correlations in meters composite depth. Sites 925 (A), 927 (B), 928 (C), and 929 (D) estimated carbonate time series were mapped in depth to Site 926, using the strategy shown in Figure 4. The age scale is the orbitally tuned age model for Site 926 (see Bickert, this volume, and Tiedemann, this volume). Solid curves represent the depth-depth correlations. Straight dashed lines represent a linear mapping, matching end points only.

the Amazon Fan by the ridge of Ceara Rise (Fig. 1). The similarity of sedimentation rates at Sites 928 and 925 could either be due to (1) similar accumulation of both carbonate and terrigenous material at the two sites, i.e., no extra dissolution at the deep site and the same influx of terrigenous material to both sites, or (2) a coincidental balance of greater carbonate dissolution and terrigenous dilution both affecting Site 928. The following discussion of relative mass accumulation rates supports the second option.

Site 926 also has sedimentation rates similar to Site 925 throughout most of the Pliocene-Pleistocene. These two sites are located closest geographically at the southern end of Ceara Rise and are farthest from the Amazon Fan, thus likely to receive less terrigenous material.

The earliest part of the record, from about 5 to $3.5 \mathrm{Ma}$, has a different relationship in relative sedimentation rates than the Pleistocene. Relative sedimentation rates generally decrease with depth during this period, with the lowest relative rates occurring at Site 929. Downslope transport of both carbonate and terrigenous material could cause some redistribution of sediments on Ceara Rise. However, downslope transport should increase sedimentation rates at depth relative to the reference. Based on the observed relative sedimentation rates, the removal of material at depth more than compensates for any additional sediments originating upslope. Even if there were no extra terrigenous flux to the deepest site (northern Site 929), the low relative sedimentation rates at the deeper sites must be due to nondeposition or dissolution of carbonate. Given the assumption of equal export productivity to all the sites because of the limited geographical range of this study, dissolution at depth is the more likely process to account for low relative sedimentation rates at depth. Qualitatively, the magnitude of the dissolution signal increases with water depth during this period of the Pliocene (Fig. 6).

\section{Relative Carbonate Mass Accumulation Rates}

We take a closer look at the effects of dissolution by examining the relative carbonate mass accumulation rates (MARs) at each site (again relative to Site 925) in Figure 7. These relative rates are calculated as follows:

$\% \mathrm{CaCO}_{3}(92 *) \times \mathrm{d}(\operatorname{depth} 92 *) / \% \mathrm{CaCO}_{3}(925) \times \mathrm{d}(\mathrm{depth} 925)$, or, the ratio of estimated percent carbonate at the two sites times the sedimentation rate ratio discussed above. In this calculation, we ignore bulk densities, which would be included in a normal mass accumulation rate calculation. The two main sedimentary components, carbonates and clays, have similar bulk densities. Also intervals of high or low carbonate among all the sites are correlated (via the depth-depth correlations in Fig 5). For these reasons, the bulk density ratio between two sites will have a negligible effect on the relative mass accumulation rate compared to the effects of changing relative percent carbonate and changing relative sedimentation rates. Low resolution bulk densities measured shipboard support this assumption (Curry, Shackleton, Richter, et al., 1995). Additionally, based on the amplitude of high-resolution GRAPE data measured shipboard, we can imagine a worst-case scenario, where, for example, a poor depth-depth map has matched two samples at the extremes of the bulk density range. Given a generous range in these sediments of $1.6-1.7 \mathrm{~g} / \mathrm{cm}^{3}$, the ratio of bulk densities would alter relative mass accumulation rates by only about $5 \%$.

Accumulation of carbonate is nearly always lower at the deepest site than at the reference site, indicating that dissolution of calcite has occurred at and below $4356 \mathrm{~m}$ water depth in the western tropical Atlantic for most of the Pliocene-Pleistocene (Fig. 7, solid curve). A similar pattern of carbonate dissolution occurs at the next deepest site (Site 928, $4012 \mathrm{~m}$ water depth) from 2.6 to $0 \mathrm{Ma}$. The amplitude of this dissolution signal is smaller with a mean relative accumulation rate closer to one than at Site 929 indicating that Site 928 has, on average, been less severely dissolved than the deepest site.

Relative carbonate accumulation rates at the shallower sites (Sites 926 and $927,3598 \mathrm{~m}$ and $3314 \mathrm{~m}$ water depth, respectively) also indicate periods of dissolution compared to Site 925 . One particular event occurs about 450-430 ka (oxygen isotope stage 12), during which time carbonate accumulation was significantly higher at the shallowest site (Site 925) than at any other site. This feature might indicate a particularly shallow lysocline, perhaps due to a weak contribution of NADW to the deep tropical Atlantic during isotope stage 12 , which has been recognized as a particularly severe glaciation (Shackleton, 1987).

The dissolution signal was less variable from 5 to $3.6 \mathrm{Ma}$. The two deeper sites (Sites 928 and 929) are almost continuously dissolved with respect to the reference. Relative accumulation at the two shal- 

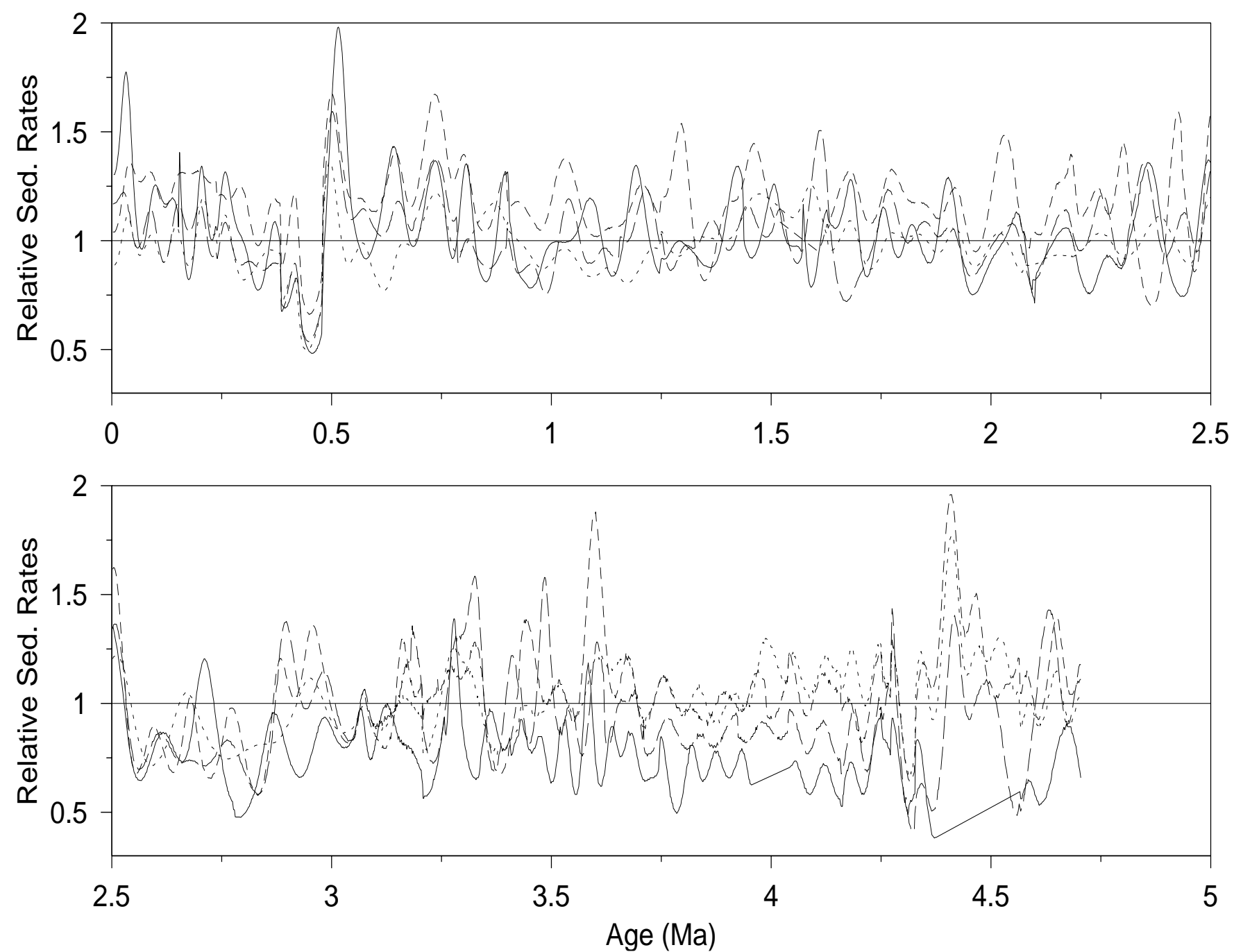

Figure 6. Relative sedimentation rates, 0-5 Ma. All sites are relative to Site 925 , which is represented by the horizontal line at one. Small dash $=$ Site $926 /$ Site

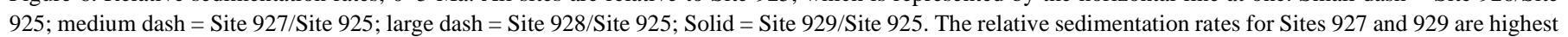

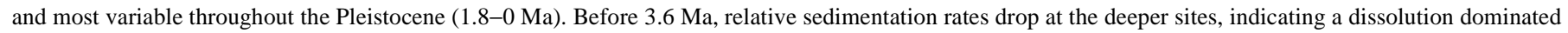
signal at depth.

lower sites (Sites 926 and 927) stays close to one during this part of the Pliocene. The dissolution trend with depth is an indication that Pliocene bottom waters were in general corrosive to carbonate. These relative mass accumulation rates indicate a rough depth cutoff for corrosive bottom water between 3600 and $4000 \mathrm{~m}$ water depth (the depths of Site 926 and 928, respectively).

\section{Relative Terrigenous Mass Accumulation Rates}

Dilution by terrigenous material affects the carbonate signals at different sites primarily as a function of location. Relative terrigenous mass accumulation rates show that differential terrigenous accumulation at Sites 927-929 (the northern sites) is responsible for the higher relative sedimentation rates at these sites (Fig. 8). Terrigenous accumulation ratios are calculated as follows:

$$
\begin{aligned}
\left(100-\% \mathrm{CaCO}_{3}[92 *]\right) & \times \mathrm{d}(\operatorname{depth} 92 *) /\left(100-\% \mathrm{CaCO}_{3}[925]\right) \\
& \times \mathrm{d}(\operatorname{depth} 925) .
\end{aligned}
$$

The same assumption discussed above of low relative variability of bulk density is used in this calculation.

From about 3.6 Ma to the present, terrigenous mass accumulation rates for the three northern sites (Sites 927-929) are on average higher than the reference. The largest differences in terrigenous mass accumulation rate are at the deepest site and to first order occur during glacial periods. Continental shelf subaerial exposure and erosion could account for the coincidence of increased terrigenous flux with sea level lowering.

From about 3.6 to $4.4 \mathrm{Ma}$, the relative terrigenous MARs at the northern sites were less variable than during the Pleistocene. Depth mapping uncertainties are partially responsible for the apparent increase in relative terrigenous MAR at Site 929 at 4.4-4.55 Ma, and at Site 928 at 4.6-4.75 Ma. Any increase in relative terrigenous accumulation is more than offset by dissolution of carbonate at the deep sites in the early Pliocene, as seen in relative sedimentation rates (Fig. $6)$.

Site 926, the southern site closest to the reference site, displays the least relative terrigenous MAR variability over the past 5 m.y. These 

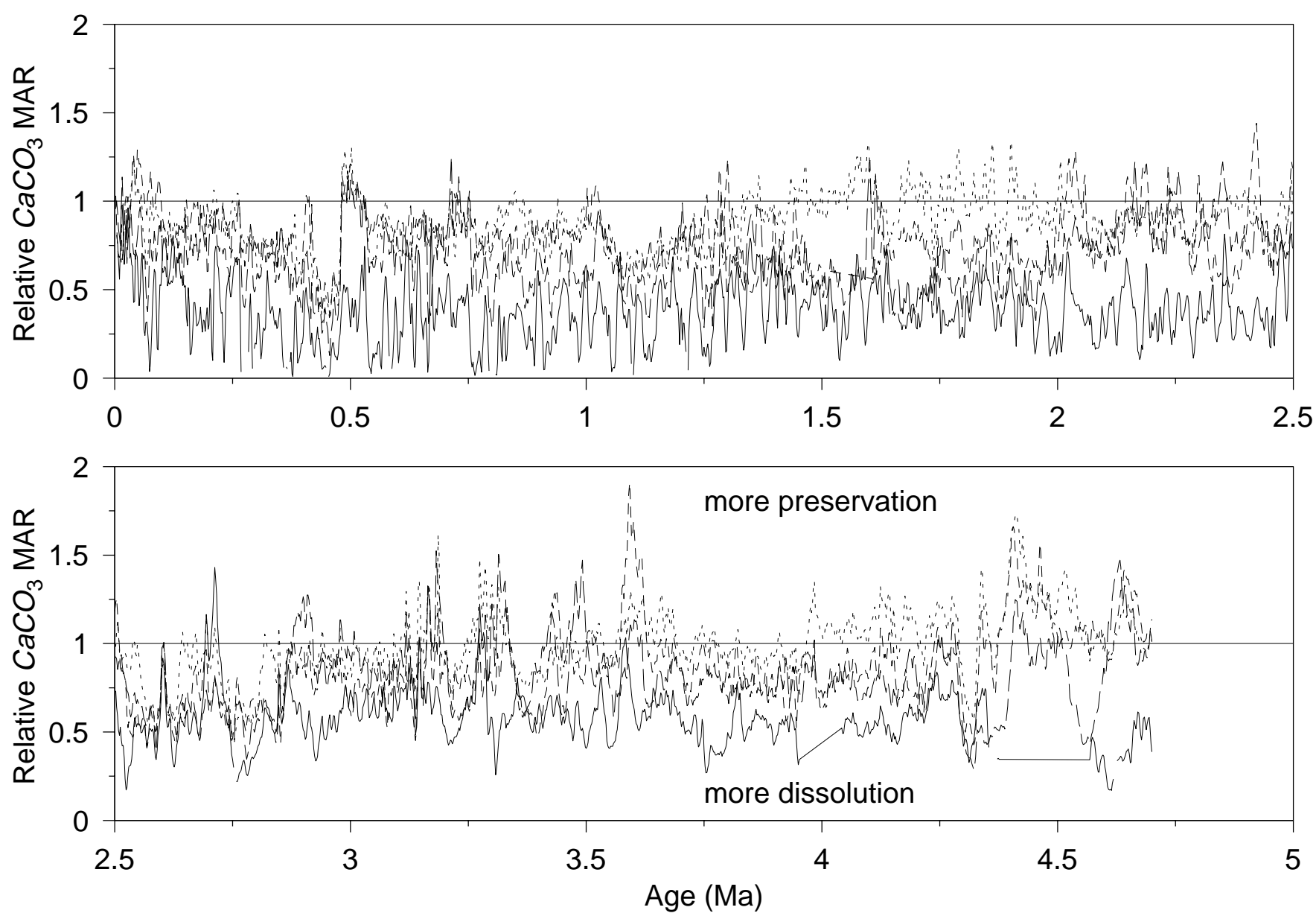

Figure 7. Relative calcium carbonate mass accumulation rates, $0-5 \mathrm{Ma}$, calculated by the ratio of estimated $\% \mathrm{CaCO}_{3}$ values multiplied by the relative sedimentation rate between two sites. We assumed that the ratio of bulk densities was close to one and did not include it in calculations of relative mass accumulation rates. All sites are represented relative to Site 925 . Small dash $=$ Site 926/Site 925; medium dash = Site 927/Site 925; large dash = Site 928/Site 925; solid = Site 929/ Site 925 . The mean relative mass accumulation rate of carbonate decreases with depth, with Sites 929/925 (solid) averaging the lowest. The record from Site 929 serves as our index of carbonate dissolution.

north-south differences indicate that terrigenous dilution is primarily a function of proximity to the Amazon Fan, the major source of terrigenous material.

\section{DISCUSSION}

We have developed two indices of climate variability, a dissolution index and a relative terrigenous flux index, both of which affect the difference in carbonate content at deep sites on Ceara Rise as compared with shallow sites. The preferred dissolution index is the relative carbonate MAR record from deep Site 929 relative to shallow Site 925 . The amplitude of this signal is largest because the deepest site is most affected by dissolution. The preferred relative terrigenous MAR signal is also from Site 929 relative to Site 925 . This is an indicator of terrigenous flux to the north and deep part of Ceara Rise.

These indices are shown with the benthic oxygen isotope record from ODP Site 849 in the eastern equatorial Pacific (Fig. 9; Mix et al., 1995c). The logical oxygen isotope record to use in this study would be from Ceara Rise sites to avoid any incompatibilities between age models from different sites. However, the Pacific Site 849 record and the oxygen isotopes for 0-1 Ma from Ceara Rise Site 926
(Curry et al., this volume) are virtually identical and are in phase. All of these data are presented on the Site 926 age model. Given the excellent correlation between the Site 849 and Site 926 isotopes, it is not inconsistent to use the Pacific oxygen isotope record. This allows us to compare the Ceara Rise data to a longer continuous record of isotopic variation.

The frequency evolution of each of these indices is compared with Site $849 \delta^{18} \mathrm{O}$ (Mix et al., 1995c). The oxygen isotope record primarily reflects global ice volume changes, and the orbital periodicities of 100 k.y., 41 k.y., and 23 k.y. dominate Pleistocene climate variability (e.g., Imbrie et al., 1984). Significant power in the 41 k.y. orbital band extends back to at least $4 \mathrm{Ma}$ in the oxygen isotope record from Site 849 (Fig. 10A). The 100 k.y. and precessional 23 k.y. cycles are strongest during the past $1 \mathrm{~m} . \mathrm{y}$.

\section{Carbonate Dissolution, Water Mass Variability, and Global Carbon Cycles}

The record of carbonate dissolution in the western tropical Atlantic has been inferred to be affected by changes in deep-water circulation (Curry and Lohmann, 1983; Curry et al., 1988; Raymo et al., 1990; Oppo and Fairbanks, 1987). Curry and Lohman (1990) com- 

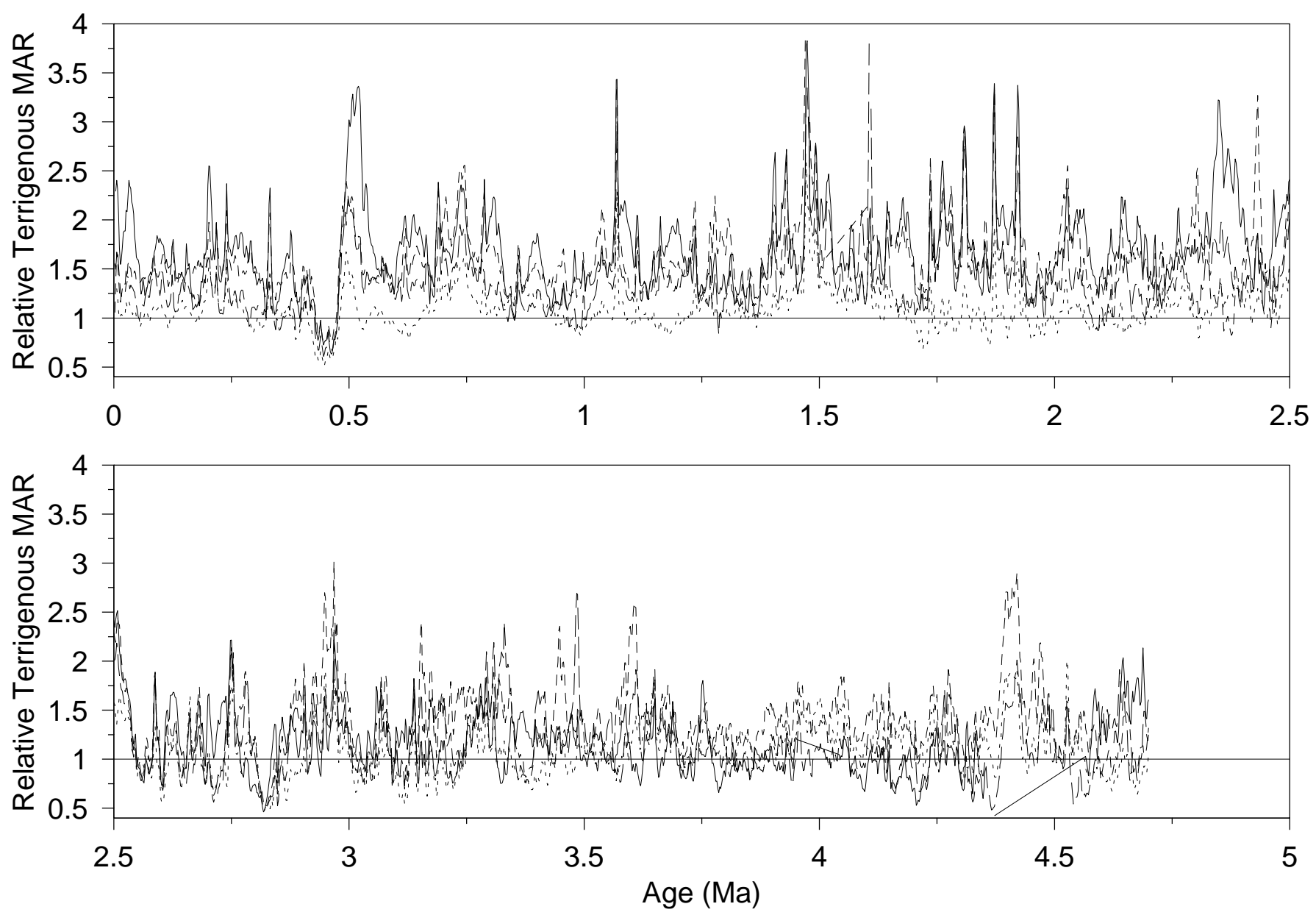

Figure 8 . Relative terrigenous mass accumulation rates, $0-5 \mathrm{Ma}$, calculated by the ratio of $\left(100-\right.$ estimated $\left.\% \mathrm{CaCO}_{3}\right)$ values multiplied by the relative sedimentation rate between two sites. As in Figure 6, we assumed that the ratio of bulk densities was close to one and did not include it in calculations of relative mass accumulation rates. All sites are represented relative to Site 925. Small dash = Site 926/Site 925; medium dash = Site 927/Site 925; large dash = Site 928/Site 925; solid $=$ Site 929/Site 925. The mean relative mass accumulation rate of noncarbonate is highest at the northern sites (Sites 927-929). The Site 929 record has the highest amplitude of variability and serves as our index for a terrigenous dilution signal.

pared dissolution patterns in the eastern and western Atlantic basins and concluded that dissolution in the tropical Atlantic is primarily a function of deep-water circulation changes. Peterson and Prell (1985) also interpreted Indian Ocean dissolution indices to be linked to regional circulation. A more widespread process that could control dissolution patterns is global atmospheric $\mathrm{CO}_{2}$ cycling (Shackleton, 1977). If massive deforestation transferred much terrestrial carbon to the ocean, globally synchronous dissolution events should occur. These events would occur on interglacial-glacial transitions (Shackleton, 1977). By comparing Atlantic and Pacific dissolution cycles, Crowley (1985) concluded that synchronous dissolution has occurred during ice growth. However, Crowley's dissolution cycles have not always been in phase during the last $0.5 \mathrm{~m}$.y., indicating that there is some imprint of regional circulation on carbonate preservation records.

The modern depth of the lysocline at Ceara Rise is primarily controlled by the depth of the mixing zone between NADW and AABW (Curry and Lohman, 1990). If we assume that this water mass boundary was present here in the past, with similar water mass characteristics, then Ceara Rise, far from deep-water source regions, may be an ideal location for monitoring temporal variability in the contributions of AABW and NADW to the deep western Atlantic. The dissolution index, relative mass accumulation rates of calcium carbonate estimated by proxies, should be sensitive to this water-mass balance. If water masses are the dominant control on dissolution, then the timing of dissolution events would define events of low NADW relative to $\mathrm{AABW}$ at the Ceara Rise.

In addition, the timing of this dissolution index in relation to ice volume could support the idea of a large influx of terrestrial carbon to the oceans on interglacial-glacial transitions. Orbital frequencies dominate the index (Fig. 10B). The 100-k.y. period in the dissolution index is strong for the past 1 m.y., similar to ice volume changes, but is also significant from about 2.25 to $3.5 \mathrm{Ma}$. Significant variance is concentrated in the obliquity band (41 k.y.) for about the past 1.75 m.y. Precession (23 k.y.) has the highest amplitude variability also during the past $1 \mathrm{~m}$.y. when Northern Hemisphere glacial cycles have dominated global climate changes. Significant variance is concentrated in all three orbital frequency bands from about 2 to $3 \mathrm{Ma}$.

If this is a water mass signal, variability in the dissolution index supports the concept of decreased NADW production associated with ice-age cycles in the Pleistocene (Oppo and Fairbanks, 1987; Raymo et al., 1990). Cross spectral analysis of the dissolution index with oxygen isotopes for 0-1 Ma shows that the two signals are coherent at all three orbital frequencies (Table 6). Maximum dissolution occurs during ice growth, before maximum glacial conditions, that is, leading $\delta^{18} \mathrm{O}$ maxima by $\sim 71^{\circ}$ at the 100 k.y. period, $\sim 68^{\circ}$ at 41 k.y. period, and $\sim 23^{\circ}$ at the $23 \mathrm{k} . y$. period (Table 6). This result is in good agreement with Imbrie et al.'s $(1992 ; 1993)$ calculated phase rela- 

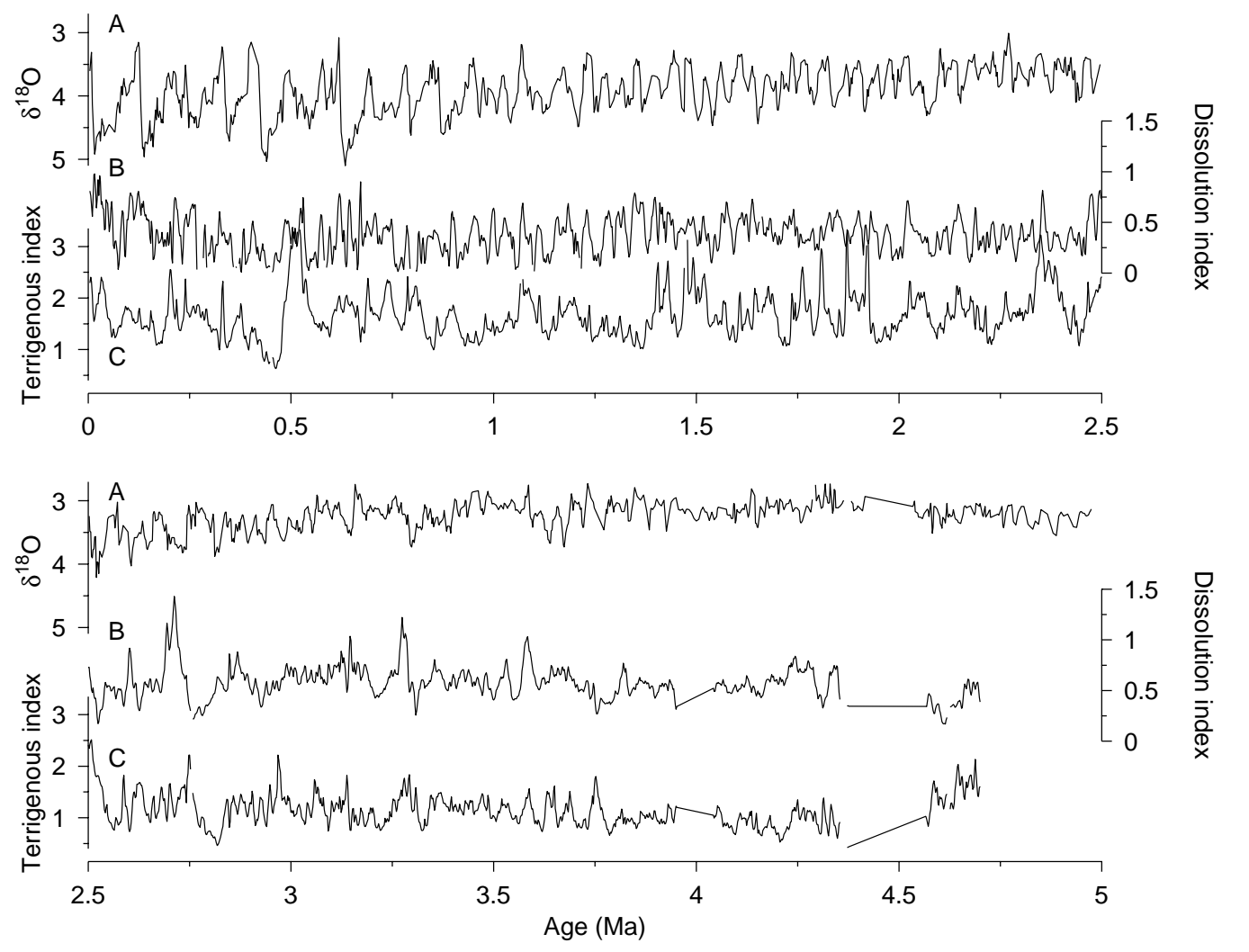

Figure 9. Time series 0-5 Ma of (A) oxygen isotopes (Site 849 in the eastern equatorial Pacific; Mix et al., 1995c) a global ice volume proxy, (B) relative carbonate mass accumulation rates Site 929/925 (Fig. 7), which serves as a dissolution index, and (C) relative terrigenous mass accumulation rates Site 929/925 (Fig. 8), which serves as a terrigenous dilution index. Values of the dissolution index of less than one indicate dissolution at the deep site. Values of the terrigenous index greater than one indicate a higher influx of terrigenous material to the deep northern site.

tionships between $\mathrm{Cd} / \mathrm{Ca}$ (Boyle and Keigwin, 1982) in the deep south Atlantic and global oxygen isotopes (ice volume lags $-\mathrm{Cd} / \mathrm{Ca}$ by $\sim 77^{\circ}$ at the $100 \mathrm{k} . \mathrm{y}$. period, by $\sim 49^{\circ}$ at the $41 \mathrm{k} . \mathrm{y}$. period, and by $\sim 27^{\circ}$ at the $23 \mathrm{k} . \mathrm{y}$. period).

The fact that this dissolution index leads ice volume supports a key prediction of SPECMAP (Imbrie et al., 1992), that Northern Hemisphere climatic forcing was translated via deep water to the southern ocean early during ice growth via early reduction in NADW production. This result, however, disagrees with the history of deepwater circulation obtained from North Atlantic carbon isotopes (Imbrie et al., 1992, 1993; Raymo et al., 1990) in which NADW reduction lags ice volume at all the orbital frequencies (Table 6).

Although the timing is consistent with SPECMAP's prediction, we still cannot rule out terrestrial carbon inputs. Dissolution events at Ceara Rise could respond in part to global carbon transfer to the oceans on ice growth. If the total dissolved $\mathrm{CO}_{2}$ in the oceans increased quickly, then the lysocline at Ceara Rise may not have been coincident with the NADW-AABW transition in the past. Comparisons with carbon isotope data (see papers, this volume) from Ceara Rise will help elucidate which process mainly drives the dissolution gradient.

\section{Terrigenous Sedimentation, Sea Level, and South American Climate}

Part of the difference in carbonate signals between Sites 925 and 929 is clearly due to terrigenous input to the deep northern site (Site 929). The effects of relative dilution on the carbonate record are represented by the relative terrigenous MAR signal between Site 929 and Site 925 . Again, this signal has the highest amplitude, largely due to its location and depth. Over the extent of the records, most of the frequency variability in the relative terrigenous index is concentrated at long periods (100 k.y. or greater; Fig. 10C), with some power at precessional periods.

For the past $1 \mathrm{~m}$.y., the terrigenous index can be compared qualitatively to ice volume. Larger influxes of terrigenous material occur at the northern sites on Ceara Rise roughly during glacial periods (Fig. 9). If the relative terrigenous flux is linked to sea level, this relationship might imply that maximum erosion of terrigenous material occurs when sea level is low (i.e., close to the shelf edge). Material that was stored on the continental shelf during high stands of sea level could erode as sea level drops. However, if shelf erosion increases as sea level lowers, one might expect that all sites on Ceara Rise would be equally affected and the relative terrigenous MAR would not vary. Much of the material from the Amazon is carried north up the coast of South America, away from the southern Ceara Rise sites, however, by the Guiana Current.

A difficulty with the interpretation that relative terrigenous flux is linked to sea level is that high-amplitude, long-period variability is also present in the pre-Pleistocene record (Fig. 10C), when ice volume (and sea level) changes were small. If sea level cannot be implicated in the Pliocene and early Pleistocene, some other climate process must dominate terrigenous flux. Crowley et al. (1992) suggest a possible mechanism based on results of energy balance models. At low latitudes the sun passes overhead twice annually, which amplifies long period temperature fluctuations in the tropics. Model output of maximum temperature variations over large tropical land masses indicate a 100-k.y. period response based on insolation forcing. Temperature changes could affect continental weathering and erosion patterns by altering rainfall variability at this long period. Such effects could explain the dominant low frequency variance in the relative terrigenous flux record pre-Pleistocene, independent of ice volume and 

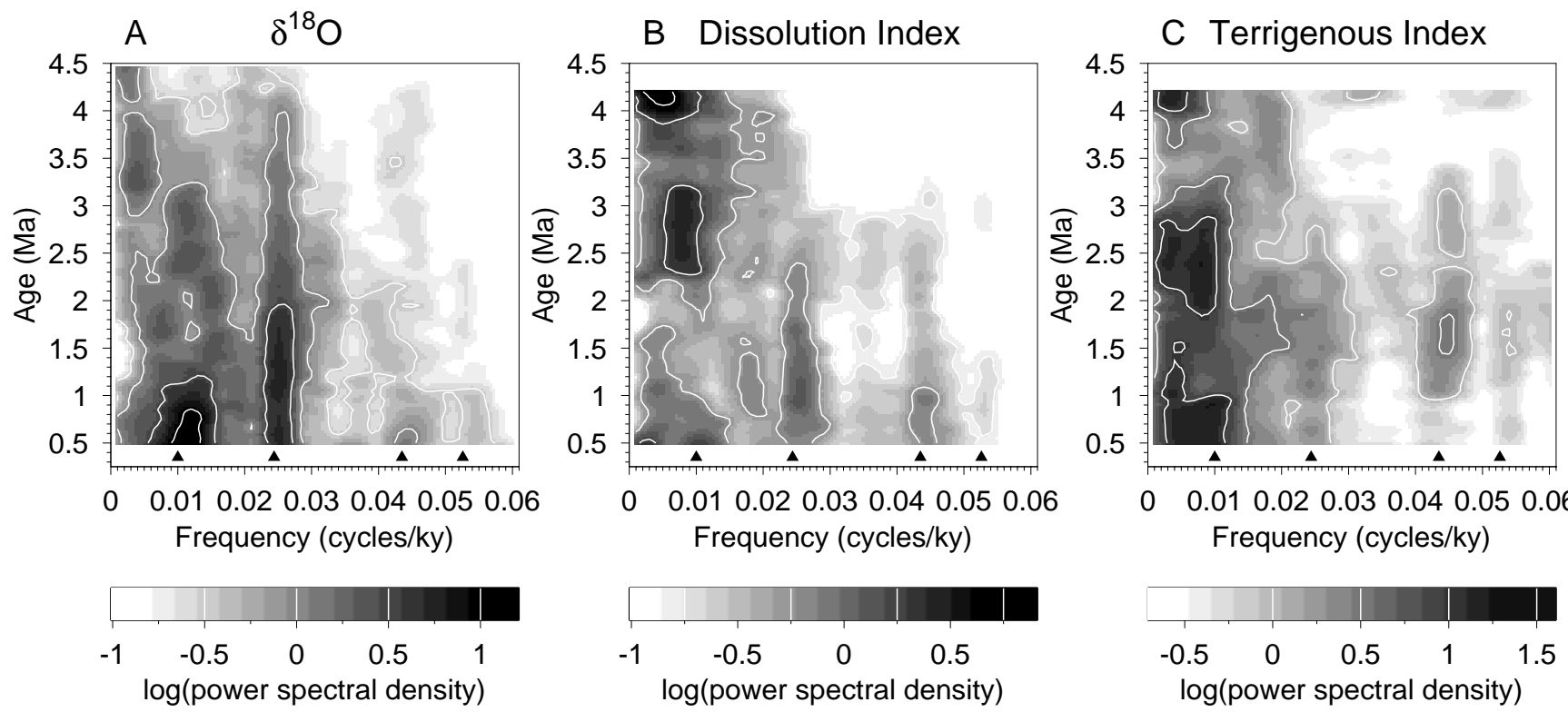

Figure 10. Evolving spectra: these maps of frequency evolution are composed of up to 80 individual time series 1 m.y. in length. Each successive time series overlaps the previous one by all but 50 k.y. Age on the y-axes is the average age of the time series (e.g., age $=0.5 \mathrm{Ma}$ represents the time series from 0 to $1 \mathrm{Ma}$ ). Triangles mark locations of orbital frequency bands (1/100 k.y., 1/41 k.y., 1/23 k.y., and 1/19 k.y. from left to right). A. Oxygen isotope record from Site 849, 0$5 \mathrm{Ma}$. Orbital frequencies dominate the spectrum over this time interval. Sampling interval $=2$ k.y., bandwidth $=0.0053$ with 11 degrees of freedom. $95 \%$ confidence interval = 0.75 in log units. B. Calcium carbonate dissolution index $\left(\mathrm{CaCO}_{3}\right.$ relative MAR, Site 929/Site 925). Time series parameters as in (A). C. Terrigenous flux proxy (terrigenous relative MAR, Site 929/Site 925). This signal is dominated by long-period fluctuations. Time series parameters as in (A).

Table 6. Cross spectral results for the dissolution index with Site 849 oxygen isotopes, 0-1 Ma.

\begin{tabular}{|c|c|c|c|c|c|c|c|}
\hline \multirow[b]{2}{*}{ Index } & \multirow[b]{2}{*}{ Source } & \multicolumn{2}{|c|}{100 k.y. } & \multicolumn{2}{|c|}{41 k.y. } & \multicolumn{2}{|c|}{23 k.y. } \\
\hline & & Coherence & Phase & Coherence. & Phase & Coherence & Phase \\
\hline $\begin{array}{l}\text { Ceara Rise: carbonate dissolution index } \\
\text { South Atlantic: }-\mathrm{Cd} / \mathrm{Ca}\end{array}$ & $\begin{array}{l}\text { This paper } \\
\text { Imbrie (1992) }\end{array}$ & $\begin{array}{l}0.94 \\
0.92\end{array}$ & $\begin{array}{l}-71 \pm 11 \\
-77 \pm 13\end{array}$ & $\begin{array}{l}0.80 \\
0.78\end{array}$ & $\begin{array}{l}-68 \pm 22 \\
-49 \pm 23\end{array}$ & $\begin{array}{l}0.88 \\
0.80\end{array}$ & $\begin{array}{l}-25 \pm 16 \\
-27 \pm 22\end{array}$ \\
\hline North Atlantic: \%NADW & Imbrie (1992) & 0.87 & $+16 \pm 15$ & 0.86 & $+5 \pm 16$ & 0.83 & $+41 \pm 17$ \\
\hline
\end{tabular}

Notes: Negative phase indicates that the index leads ice volume (e.g., maximum dissolution leads maximum ice volume by $71^{\circ}$ at $100 \mathrm{k} . \mathrm{y}$. periodicities). Positive phase indicates that the index lags ice volume. Phase units are degrees.

sea level. Mix et al, (1995b) found that sedimentation rate variability in the eastern tropical Pacific was consistent with the Crowley et al. (1992) hypothesis. Climate variability in the tropics at 100-k.y. periods could be independent of ice volume, with the effects recorded off both coasts of South America.

\section{CONCLUSIONS}

1. Long time series of carbonate variability can be estimated empirically from nonintrusive proxy data (reflectance and magnetic susceptibility) with RMS errors ranging from $4 \%$ to $7 \%$ $\mathrm{CaCO}_{3}$. These errors are smaller than previously possible using similar proxy techniques and are acceptable given the wide range of carbonate variability in Ceara Rise sediments. A regional calibration equation is robust among the sites, but localized calibrations can improve statistical measures of equation success (higher $\mathrm{r}^{2}$, lower RMSE).

2. Accumulation rates of calcium carbonate decrease with increasing water depth on Ceara Rise, indicating that the deeper sites have undergone some degree of dissolution for the past 5 m.y. The amplitude of the dissolution signal and the mean strength of dissolution both increase in the Pleistocene.

3. Dissolution varies at the deeper sites on G-I time scales during the Pleistocene. Dissolution events lead maximum ice volume at all orbital frequencies. Phase relationships are consistent with a deep south Atlantic nutrient proxy used by Imbrie et al. (1992; 1993) indicating early climate responses in the Southern Ocean. If deep ocean circulation has driven dissolution from 0 to $1 \mathrm{Ma}$, then export of NADW decreased early relative to maximum ice, perhaps forming a link between Northern Hemisphere climate forcing and documented early responses in the southern ocean. This result indicating early deep-water changes is quite different than the view of deep-water variability derived from carbon isotope data near the source of NADW. One strength of the dissolution index presented here is the location of Ceara Rise in the mixing zone between northern and southern source deep water. Carbonate dissolution signals here should be very sensitive to the balance of NADW and $\mathrm{AABW}$ contributions to western tropical Atlantic deep water if the lysocline boundary coincided with the mixing zone $0-1 \mathrm{Ma}$ as it does today. In addition, the dissolution signal may in part record a global transient response of the carbonate system to the transfer of carbon between the terrestrial and oceanic reservoirs.

4. Carbonate percentages are affected by terrigenous influx preferentially at sites nearest the Amazon Fan. Terrigenous fluxes to the deep sites relative to those at shallow Site 925 were highest during glacial stages in the Pleistocene. The prevalence of $100 \mathrm{k} . \mathrm{y}$. period cycles before $1 \mathrm{Ma}$, at times older than 
large fluctuations in Northern Hemisphere ice volume, suggests that sea level is not the primary mechanism controlling terrigenous sedimentation at the northern Ceara Rise. The long-period relative terrigenous flux cycle alternatively could be related to a low-latitude continental climate process acting independently of ice, particularly in the Pliocene-early Pleistocene.

\section{ACKNOWLEDGMENTS}

Thanks to Jerry McManus and William Balsam for helpful reviews of this manuscript, Bill Rugh for much instrumental help, and Walter Hale and Alex Wueblers for their assistance at the ODP Bremen Core Repository. Carbonate data used in this manuscript were provided by Terri King, Bill Curry, and Rindy Ostermann. This work was supported by USSSP grant \#154-20868b.

\section{REFERENCES}

Balsam, W.L., Otto-Bliesner, B.L., and Deaton, B.C., 1995. Modern and last glacial maximum eolian sedimentation patterns in the Atlantic Ocean interpreted from sediment iron oxide content. Paleoceanography, 10:493-508.

Bloomfield, P., 1976. Fourier Analysis of Time Series: An Introduction: New York (Wiley).

Boyle, E.A., and Keigwin, L.D., 1982. Deep circulation of the North Atlantic over the last 200,000 years: geochemical evidence. Science, 218:784787.

Crowley, T.J., 1985. Late Quaternary changes in the North Atlantic and Atlantic/Pacific comparisons. In Sundquist, E.T., and Broecker,W.S. (Eds.), The Carbon Cycle and Atmospheric $\mathrm{CO}_{2}$ : Natural Variations Archean to Present. Washington, D.C. (American Geophysical Union), 271-284.

Crowley, T.J., Kim, K.Y., Mengel, J.G., and Short, D.A., 1992. Modeling the 100,000-year climate fluctuations in pre-Pleistocene time series. Science, 255: 705-707.

Curry, W.B., Duplessy, J.C., Labeyrie, L.D., and Shackleton N.J., 1988. Changes in the distribution of $\delta^{13} \mathrm{C}$ of deep water $\Sigma \mathrm{CO}_{2}$ between the last glaciation and the Holocene. Paleoceanography, 3:317-341.

Curry, W.B., and Lohmann, G.P., 1983. Reduced advection into Atlantic Ocean deep eastern basins during last glacial maximum. Nature, 306:577-580

Curry, W.B., and Lohmann, G.P., 1990. Reconstructing past particle fluxes in the tropical Atlantic ocean. Paleoceanography, 5:487-505.

Curry, W.B., Shackleton, N.J., Richter, C., et al., 1995. Proc. ODP, Init. Repts., 154: College Station, TX (Ocean Drilling Program).

Deaton, B.C., and Balsam, W.L., 1991. Visible spectroscopy-a rapid method for determining hematite and goethite concentration in geological materials. J. Sediment. Petrol., 61:628-632.

Gaffey, S.J., 1986. Spectral reflectance of carbonate minerals in the visible and near infrared (0.35-2.55 microns): calcite, aragonite, and dolomite. Am. Mineral., 71:151-162.

Imbrie, J., Hays, D., Martinson, D.G., McIntyre, A., Mix, A.C., Morley, J.J., Pisias, N.G., Prell, W.L., and Shackleton, N.J., 1984. The orbital theory of Pleistocene climate: support from a revised chronology of the marine $\delta^{18} \mathrm{O}$ record. In Berger, A.L., et al., Milankovitch and Climate, Pt. 1, NATO AST Ser. C, 126: Dordrecht (D. Riedel), 269-305.
Imbrie, J., Berger, A., Boyle, E., Clemens, S., Duffy, A., Howard, W., Kukla, G., Kutzbach, J., Martinson, D., McIntyre, A., Mix, A., Molfino, B., Morley, J., Peterson, L., Pisias, N., Prell, W., Raymo, M., Shackleton, N., and Toggweiler, J., 1993. On the structure and origin of major glaciation cycles, 2. The 100,000-year cycle. Paleoceanography, 8:699-735.

Imbrie, J., Boyle, E.A., Clemens, S.C., Duffy, A., Howard, W.R., Kukla, G., Kutzbach, J., Martinson, D.G., McIntyre, A., Mix, A.C., Molfino, B., Morley, J.J., Peterson, L.C., Pisias, N.G., Prell, W.L., Raymo, M.E., Shackleton, N.J., and Toggweiler, J.R., 1992. On the structure and origin of major glaciation cycles, 1. Linear responses to Milankovitch forcing. Paleoceanography, 7:701-738.

Martinson, D.G., Menke, W., and Stoffa, P., 1982. An inverse approach to signal correlation. J. Geophys. Res., 87:4807-4818.

Mix, A.C., Harris, S.E., and Janecek T.R., 1995a. Estimating lithology from nonintrusive reflectance spectra: Leg 138. In Pisias, N.G., Mayer, L.A., Janecek, T.R., Palmer-Julson A., and van Andel, T.H. (Eds.), Proc. ODP, Sci. Res. 138: College Station, TX (Ocean Drilling Program), 413-428.

Mix, A.C., Le, J., and Shackleton N.J., 1995b. Benthic foraminiferal stable isotope stratigraphy of Site 846: 0-1.8 Ma. In Pisias, N.G., Mayer, L.A., Janecek, T.R., Palmer-Julson A., and van Andel, T.H. (Eds.), Proc. ODP, Sci. Res. 138: College Station, TX (Ocean Drilling Program), 839-854.

Mix, A.C., Pisias N.G., Rugh, W., Wilson, J., Morey, A., and Hagelberg, T.K., 1995c. Benthic foraminifer stable isotope record from Site 849 (0$5 \mathrm{Ma}$ ): Local and global climate changes. In Pisias, N.G., Mayer, L.A., Janecek, T.R., Palmer-Julson A., and van Andel, T.H. (Eds.), Proc. ODP, Sci. Res. 138: College Station, TX (Ocean Drilling Program), 371-412.

Mix, A.C., Rugh, W., Pisias, N.G., Veirs, S., Leg 138 Shipboard sedimentologists (Hagelberg, T., Hovan, S., Kemp, A., Leinen, M., Levitan, M., Ravelo, C.), and Leg 138 Scientific Party, 1992. Color reflectance spectroscopy: a tool for rapid characterization of deep-sea sediments. In Mayer, L.A., Pisias, N.G., Janecek, T.R., et al., Proc. ODP, Init. Repts, 138: College Station, TX (Ocean Drilling Program), 67-77.

Oppo, D.W., and Fairbanks, R.G., 1987. Variability in the deep and intermediate water circulation of the Atlantic Ocean: Northern Hemisphere modulation of the Southern Ocean. Earth Planet. Sci. Lett., 86:1-15.

Ostermann, D.R., Karbott, D., and Curry, W.B., 1990. Automated system to measure the carbonate concentration of sediments. WHOI Tech. Rept. 90-103.

Peterson, L.C., and Prell W.L., 1985. Carbonate preservation and rates of climatic change: An 800 ky record from the Indian Ocean. In Sundquist, E.T., and Broecker, W.S. (Eds.), The Carbon Cycle and Atmospheric $\mathrm{CO}_{2}$ : Natural Variations Archean to Present. Geophys. Monogr., Am. Geophys. Union, 32:251-270.

Raymo, M.E., Ruddiman, W.F., Shackleton, N.J., and Oppo, D.W., 1990. Evolution of Atlantic-Pacific $\delta^{13} \mathrm{C}$ gradients over the last 2.5 m.y. Earth Planet. Sci. Lett., 97:353-368.

Shackleton, N.J., 1977. Carbon-13 in Uvigerina: tropical rainforest history and the equatorial Pacific carbonate dissolution cycles. In Anderson, N.R., and Malahoff, A., (Eds.), The Fate of Fossil Fuel $\mathrm{CO}_{2}$ in the Oceans. New York (Plenum), 401-427.

Shackleton, N.J., 1987. Oxygen isotopes, ice volume and sea level. Quat. Sci. Rev., 6:183-190.

Ms 154SR-114

Date of initial receipt: 4 December 1995

Date of acceptance: 19 August 1996 